\title{
Progressive multifocal leukoencephalopathy and the spectrum of JC virus-related disease
}

Irene Cortese $\mathbb{1}^{1 凶}{ }^{\otimes}$, Daniel S. Reich $\mathbb{B}^{2}$ and Avindra Nath ${ }^{3}$

Abstract | Progressive multifocal leukoencephalopathy (PML) is a devastating CNS infection caused by JC virus (JCV), a polyomavirus that commonly establishes persistent, asymptomatic infection in the general population. Emerging evidence that PML can be ameliorated with novel immunotherapeutic approaches calls for reassessment of PML pathophysiology and clinical course. PML results from JCV reactivation in the setting of impaired cellular immunity, and no antiviral therapies are available, so survival depends on reversal of the underlying immunosuppression. Antiretroviral therapies greatly reduce the risk of HIV-related PML, but many modern treatments for cancers, organ transplantation and chronic inflammatory disease cause immunosuppression that can be difficult to reverse. These treatments - most notably natalizumab for multiple sclerosis - have led to a surge of iatrogenic PML. The spectrum of presentations of JCV-related disease has evolved over time and may challenge current diagnostic criteria. Immunotherapeutic interventions, such as use of checkpoint inhibitors and adoptive $T$ cell transfer, have shown promise but caution is needed in the management of immune reconstitution inflammatory syndrome, an exuberant immune response that can contribute to morbidity and death. Many people who survive PML are left with neurological sequelae and some with persistent, low-level viral replication in the CNS. As the number of people who survive PML increases, this lack of viral clearance could create challenges in the subsequent management of some underlying diseases.

Progressive multifocal leukoencephalopathy (PML) is a rare, debilitating and often fatal disease of the CNS caused by JC virus (JCV). JCV commonly establishes asymptomatic, lifelong persistent or latent infection in the general population but, in patients with prolonged and profound compromise of cellular immunity, JCV can reactivate from sites of latency and undergo sequential genomic rearrangements. This intrahost viral evolution allows an otherwise benign virus to cause lytic infection of CNS glial cells and thus PML.

Before the AIDS pandemic, PML was a rare complication in patients with immune compromise related to lymphoproliferative disease. The AIDS pandemic led to the first surge in occurrence of PML. The introduction of highly effective antiretroviral therapies decreased the incidence of PML in AIDS, although HIV remains the single greatest contributor to the total number of PML cases. In the past decade, a second, smaller surge has been seen, associated with the development of modern treatments for cancers, organ transplantation and chronic inflammatory disease, most notably natalizumab for multiple sclerosis. Taken together, HIV, lymphoproliferative disease and multiple sclerosis account for the majority of PML cases.

No antiviral therapies are available for JCV infection or PML, and survival depends on reversal of the underlying immunosuppression. Emerging evidence indicates that when immunosuppression cannot be readily reversed, novel immunotherapeutic strategies that are designed to augment antiviral immune responses could be of benefit. In light of these exciting developments, we provide here an overview of the pathobiology of JCV infection and PML and discuss the evolving clinical presentation of PML and atypical JCV-related CNS manifestations. We then review the novel immunotherapeutic approaches to the treatment of this disease that offer some promise for increased survival.

\section{JCV and disease mechanisms}

An ancient and ubiquitous virus. JCV was the first of two human polyomaviruses to be isolated in 1971 (REF. ${ }^{1}$ ). The family Polyomaviridae has since expanded, 


\section{Key points}

- Progressive multifocal leukoencephalopathy (PML) is a rare, debilitating and often fatal disease of the CNS caused by JC virus (JCV).

- JCV establishes asymptomatic, lifelong persistent or latent infection in immune competent hosts, but impairment of cellular immunity can lead to reactivation of JCV and PML.

- PML most commonly occurs in patients with HIV infection or lymphoproliferative disease and in patients who are receiving natalizumab for treatment of multiple sclerosis.

- The clinical phenotype of PML varies and is shaped primarily by the host immune response; changes in the treatment of underlying diseases associated with PML have changed phenotypes over time.

- Other clinical manifestations of JCV infection have been described, including granule cell neuronopathy.

- Survival of PML depends on reversal of the underlying immunosuppression; emerging immunotherapeutic strategies include use of checkpoint inhibitors and adoptive T cell transfer.
Seroconversion

Development of detectable antibodies in the blood

directed at an infectious agent

in response to primary

infection

Viral reactivation Emergence of a virus from latency, leading to productive viral replication and 11 additional human viruses of this family have been identified in the past decade ${ }^{2}$. The number and variety of human polyomaviruses reflect their ability to propagate at low levels without causing disease and to evade clearance by the immune system; most polyomaviruses establish asymptomatic infection in healthy hosts and are pathogenic only in the setting of severe immunosuppression ${ }^{3}$.

$\mathrm{JCV}$ is an ancient, ubiquitous virus that seems to have co-evolved with human populations ${ }^{2,4,5}$. JCV infection typically occurs in childhood via horizontal transmission through long-term cohabitation, most commonly from parent to child ${ }^{6}$. Seroconversion increases with age and reaches $\sim 60-80 \%$ by the age of 70 years $^{7-11}$. Transmission is thought to occur via person-to-person contact and contaminated surfaces, food and water ${ }^{12,13}$, and the virus enters through the oropharynx. Consistent with this notion, JCV can be isolated from tonsil and gut lymphatic tissue of infected individuals, which might be sites of primary infection ${ }^{14,15}$.

Haematogenous spread mediates infection of secondary sites, including kidney, bone marrow, lymphoid tissue and possibly brain. Within bone marrow and lymphoid tissue, precursor B cells, $\mathrm{CD} 34^{+}$haematopoietic progenitor cells and tonsillar stromal cells can all harbour JCV ${ }^{16}$. True viral latency - defined by detection of transcriptionally inactive virus - can be established at secondary sites in immunocompetent hosts, and JCV infection of uroepithelium commonly results in persistent infection, which involves asymptomatic replication and enables intermittent detection of the virus in the urine in $\sim 30 \%$ of the general population ${ }^{17}$. Indeed, JCV is a common contaminant of urban sewage, which is thought to be the major source of environmental exposure ${ }^{18}$. Findings from longitudinal analysis of urine samples suggest that infection is persistent rather than repeated ${ }^{19}$. The ubiquity of JCV contrasts with the rarity of its pathological expression - even among susceptible, immunocompromised individuals. This discrepancy has at least in part been explained by advances in our understanding of the pathobiology of JCV infection ${ }^{20}$.
Structure and genome. Polyomaviruses are small, nonenveloped, double-stranded DNA viruses. Entry into host cells occurs primarily via attachment of viral particles to sialic acid moieties, followed by clathrin-mediated endocytosis ${ }^{21}$. In vitro studies have shown that viral entry into glial cells is facilitated by the $5-\mathrm{HT}_{2 \mathrm{~A}}$ serotonin receptor. Viral replication, protein synthesis and assembly of viral particles rely on host cellular machinery ${ }^{21}$.

The circular genome of JCV contains two coding regions: the early viral gene region, which encodes regulatory proteins (large and small tumour antigens), and the late viral gene region, which principally encodes structural proteins (VP1, VP2 and VP3) and the accessory regulatory protein agnoprotein ${ }^{21}$. The early viral gene region and the late viral gene region are separated by a regulatory non-coding control region (NCCR) ${ }^{21}$, which contains the origin of replication and regulatory regions for early and late transcription. Importantly, this region includes host cell-specific DNA and transcription factor-binding sites. The NCCR is the region of greatest sequence diversity and determines the efficiency of viral replication and cellular tropism ${ }^{22-24}$. Thus, host cell permissiveness is determined at the transcriptional level by the expression of specific regulatory proteins, among them the nuclear factor 1 (NFI) family and NFIX (which is highly expressed in brain), rather than by the expression of cell-surface receptors that mediate viral entry ${ }^{25}$.

Sequencing of viral isolates from healthy and diseased individuals has demonstrated that JCV found in urine has a stable genetic architecture with conserved sequence blocks and only modest genomic variation of the NCCR. This stable viral variant has been referred to as the archetype virus and is the transmissible form found in the environment ${ }^{12,19,26}$. Archetype virus replicates poorly in glial cells ${ }^{27}$ and is rarely detected in the cerebrospinal fluid (CSF) of individuals with $\mathrm{PML}^{28}$. Instead, viral isolates from the brain, CSF and blood of patients with PML most commonly include a complex, patient-specific mixture of JCV quasispecies with highly variable genetic rearrangement of the NCCR; these variants are referred to as prototype viruses or rearranged variants. Notably, despite substantial differences in the NCCR, only one major VP1 serotype exists that is indistinguishable between archetype and prototype virus ${ }^{29}$; these variants can be identified only by sequencing.

Intrahost viral evolution. Rearranged NCCRs do not carry simple point mutations but rather carry complex deletions and tandem duplications derived from the preexisting archetype sequences ${ }^{30,31}$. These rearrangements are thought to result from sequential, replication-driven homologous recombination events in the setting of viral reactivation, and might be favoured by the presence of palindromic sequences within the JCV genome. Such recombination events might not be uncommon in individuals with immunosuppression even if they do not go on to develop PML, and the vast majority of NCCR rearrangements are likely to generate non-viable sequences. However, in rare cases, rearrangement can give the virus new tissue tropism and pathogenic potential owing to 
the introduction of tissue-specific response elements and an increase in replicative ability in glial cells ${ }^{32}$. Indeed, sequence analysis of rearranged NCCRs demonstrates that negative transcription control signals are lost and positive transcription control signals are created or duplicated $^{22,27}$, leading to increases in gene expression and the rate of replication in prototype viruses compared with the gene expression and rate of replication in the archetype strain ${ }^{31}$. Whereas early gene expression and late gene expression in archetype and rearranged viral variants were comparable in renal-derived cell lines (HEK293), late gene expression was suppressed in archetype strains in glioblastoma cell lines. Such differences could contribute to tissue-specific replicative advantages of rearranged variants in vivo ${ }^{33}$.

The CSF of patients with PML contains multiple NCCR rearrangements, but one sequence usually dominates. During active infection and as viral load increases, the dominant sequence can change over just a few days ${ }^{28,31,34}$. Moreover, the majority species can differ between anatomical compartments within the same individual $^{31}$, and distinct JCV strains have been found in different areas of the brain of individuals with $\mathrm{PML}^{28,35,36}$. After successful resolution of PML and a decrease in the JCV load, residual detectable NCCR variants remain stable $^{34}$.

Overall, therefore, PML involves a highly dynamic process driven by uncontrolled JCV replication. The rarity of the disease is at least partially explained by the fact that a rearranged NCCR confers replicative advantage and neurotropism and that these rearrangements are newly and randomly generated in each individual over the course of infection.

Getting to the brain. The specific site and mechanism of acquisition of neurotropism of JCV are not known. Kidney, bone marrow, circulating white blood cells (including B cell lineages and $\mathrm{CD} 34^{+}$haematopoietic progenitor cells) and the brain itself have all been proposed as sites where viral reactivation can occur, but definitive evidence is lacking and sites might not be mutually exclusive ${ }^{22}$.

When and how JCV reaches the CNS also continues to be a matter of debate ${ }^{20}$. JCV has been identified in brains from healthy individuals as well as the brains of people who have a suppressed immune system without $\mathrm{PML}^{37-40}$, but the relevance of this reservoir in the brain is uncertain. Therefore, whether PML results from entry of already-rearranged JCV to the CNS - via infected leukocytes, passive transportation on the surface of leukocytes or as unbound virus - or from reactivation and neuroadaptation of latent virus in the CNS has not been resolved $^{20,41,42}$.

Pathogenesis of PML. PML occurs only exceptionally in immunocompetent hosts, so prolonged impairment of cellular immunity is clearly a permissive condition for viral reactivation. $\mathrm{CD}^{+} \mathrm{T}$ cell reactivity in particular is associated with prevention and resolution of disease $\mathrm{e}^{43,44}$. JCV reactivation is most common in patients with deficiencies of $\mathrm{CD} 4^{+} \mathrm{T}$ cells, as in HIV infection, and $\mathrm{CD} 4^{+} \mathrm{T}$ cell counts correlate with prognosis in $\mathrm{PML}^{24,45}$.
Viral reactivation and JCV viraemia can be seen if the cellular immune response to JCV is impaired, even in patients without PML who have been treated with immunosuppressive regimens ${ }^{46,47}$. This reactivation is associated with increased variability of NCCR rearrangements, indicating accumulation of replication-driven mutational events ${ }^{20,37-40,48-50}$.

PML does not occur uniformly among immunocompromised patient populations, suggesting that other risk-modifying factors are at play. In some cases, viral mutations could account for increased neurovirulence. For example, mutations in VP1 can affect pathogenesis of PML, and some variants seem to be associated with heightened susceptibility or aggressive disease $\mathrm{e}^{51-54}$. Host genetic risk factors have also been identified; for example, individuals with the $H L A-D R B 1{ }^{*} 0401$ allele were found to have limited ability to mount robust antiviral responses $^{55}$, and polymorphisms of the tumour suppressor protein p53 - a binding site of large tumour antigen that may modulate viral gene expression - can increase susceptibility ${ }^{56}$. More recently, use of whole-exome sequencing has identified 19 rare germ line PML risk variants that affect 17 genes related to immune function ${ }^{57}$. Determining how these host genetic factors influence susceptibility to PML will be of great interest and could offer opportunities for personalized pharmacovigilance strategies. The most striking risk factors for the development of PML, however, seem to be the particular underlying disease and the immunosuppressive drug used (FIG. 1).

HIV infection is strongly associated with PML, which developed in as many as $5 \%$ of people with HIV at the height of the AIDS pandemic. This association might in part be explained by a synergistic effect of HIV and JCV co-infection. In vitro studies have shown the HIV transactivator protein Tat promotes transcription and replication of JCV archetype ${ }^{58,59}$ and emergence of JCV from latency ${ }^{31}$.

The cytokine milieu that is specific to the underlying disease could also contribute to JCV reactivation. Several transcription factors that have been implicated in JCV replication, including nuclear factor $\kappa$-light-chain enhancer of activated B cells (NF- $\kappa \mathrm{B}$ ), T cell transcription factor NFAT4 and CCAAT/enhancer-binding protein- $\beta$, are downstream of proinflammatory cytokines, such as tumour necrosis factor (TNF) ${ }^{3}$. Several features of B cells could also support JCV replication and contribute to the relatively high risk of PML in chronic lymphocytic leukaemia and other B cell lymphoprolierative diseases. For example, the transcription factor Spi-B, which is involved in controlling the differentiation and maturation of B cells, can also regulate JCV gene expression and the expression of the recombinase enzymes RAG1 and RAG2, which mediate immunoglobulin gene rearrangements have been proposed as facilitatorse of NCCR rearrangement ${ }^{60,61}$. The peripheral mobilization of $\mathrm{CD} 34^{+}$haematopoietic precursor cells and $\mathrm{CD} 19^{+}$ precursor $\mathrm{B}$ cells from the bone marrow in patients who are undergoing treatment with natalizumab - which is associated with a high risk of PML - has been proposed to facilitate JCV reactivation and dissemination ${ }^{62}$. However, even if such conditions do facilitate JCV 


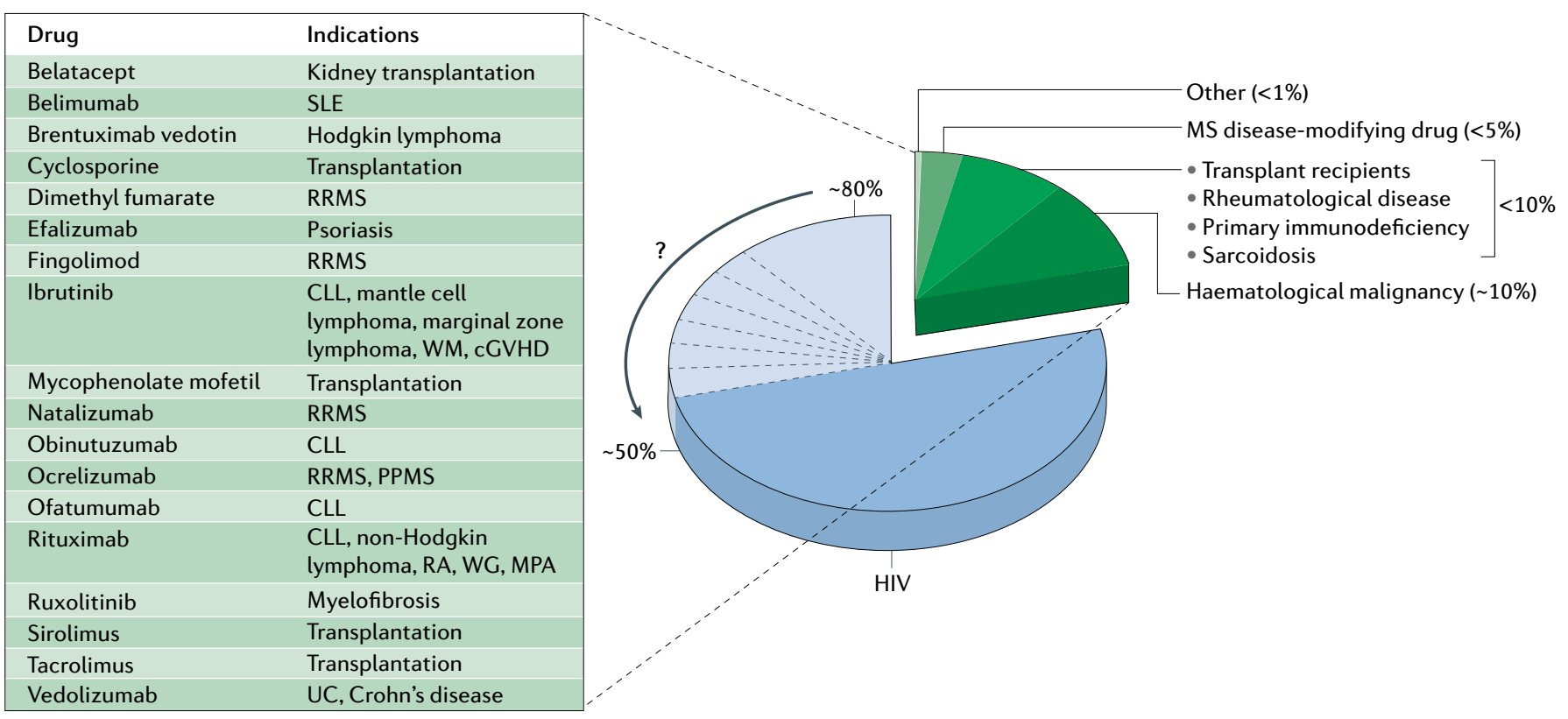

Fig. 1 | Risk factors for PML. The chart shows the estimated proportion of progressive multifocal leukoencephalopathy $(\mathrm{PML})$ cases that occur in different patient groups. PML is not a reportable disease, so accurate estimates of incidence among patient populations are lacking. Over the past four decades, HIV infection has accounted for the vast majority of PML cases $(\sim 80 \%)^{195}$, although evidence suggests that the proportion is shifting towards lower numbers ${ }^{187}$, as indicated by the arrow. Approximately $10 \%$ of PML cases occur among patients with haematological malignancy, most commonly non-Hodgkin lymphoma and chronic lymphocytic leukaemia (CLL). Natalizumab-associated PML accounts for the third-largest single patient population, estimated at less than $5 \%$ of cases. Approximately $10 \%$ of PML cases occur in other patients with identifiable immunosuppressed states, including transplant recipients and patients with underlying chronic inflammatory or rheumatological disease. In rare cases, patients without a clearly identifiable predisposing condition develop PML; this occurs more commonly among elderly patients. The inset table shows the growing number of drugs associated with a risk of PML and that currently carry a labelled warning; such medications often contribute to the risk of PML among susceptible patient populations. cGVHD, chronic graft-versus-host disease; MPA, microscopic polyangiitis; MS, multiple sclerosis; PPMS, primary progressive multiple sclerosis; RA, rheumatoid arthritis; RRMS, relapsing-remitting multiple sclerosis; SLE, systemic lupus erythematosus; UC, ulcerative colitis; WG, Wegener granulomatosis; WM, Waldenstrom macroglobulinaemia. reactivation, once replication can proceed unhindered by $\mathrm{T}$ cells, the emergence of neurotropic quasispecies is probably independent of any disease-specific cofactor $^{31}$.

The knowledge outlined above favours a threestage model of PML pathogenesis (FIG. 2). In stage 1, non-pathogenic archetype virus establishes persistent infection in kidney and possibly latent infection at other secondary sites in immunocompetent individuals; for most people, infection remains in this stage of subclinical infection. Stage 2 occurs most commonly with prolonged and profound impairment of cellular immunity, which permits viral reactivation and the accumulation of genetic rearrangements of the NCCR that leads to emergence of neuropathogenic JCV prototypes. The virus could gain access to the brain during stage 1 or stage 2 . Stage 3 is the clinical manifestation of $\mathrm{PML}^{63}$. The current diagnostic criteria for definite PML are stringently based on the demonstration of JCV in brain tissue or, in the context of a typical MRI and clinical presentation, the demonstration of JCV DNA in the CSF $^{64}$ (TABLE 1).

Given that survival has increased with successful immune reconstitution, a fourth stage can be proposed, in which the host-virus equilibrium is re-established and, in some patients, persistent infection with a rearranged pathogenic virus ensues. Indeed, viral persistence with low copy detection in the CSF for years after clinical stabilization has been observed in some people who have survived $\mathrm{PML}^{65,66}$. The risk that PML will recur in these patients is unknown but is not negligible ${ }^{67}$ (FIG. 2).

\section{The evolving phenotype of PML}

PML arises in various populations of immunologically vulnerable patients as a late and rare manifestation of JCV infection. As new vulnerable populations have emerged (FIG. 3), the clinical expression has evolved. The clinical presentations form a continuum, primarily shaped by the host immune response. At one end of the spectrum is the absence of meaningful antiviral immune activity, which was typical of the earliest descriptions of PML and which we refer to as 'classic PML.' In the middle is a gradient of presentations with a combination of clinical, imaging and histopathological features that indicate various degrees of preserved immune function or that result from immune reconstitution. We refer to these presentations as 'inflammatory PML.' At the extreme of this gradient is extensive inflammation that can in itself lead to immune-mediated injury - this presentation is called 'progressive multifocal leukoencephalopathy immune reconstitution inflammatory syndrome' (PML IRIS). Although no consensus definition exists for IRIS across PML patient populations, this term is most often used to indicate clinical worsening attributed to inflammation.

The features of PML that were reported in the decades after its initial clinical description came from 
observations in severely immunocompromised individuals with no possibility of immune reconstitution. The AIDS pandemic heralded a new era in the epidemiology of PML because a surge in cases was seen between the first report of PML in AIDS in 1982 and the introduction of combination antiretroviral therapy (cART) in 1996, but the clinical features seen in those years were similar to what had been previously described. Classic PML remains the most severe and most common expression of the disease today.

Classic PML. The first clinical descriptions of PML date back to 1958, when it was described in eight patients with haematological malignancy ${ }^{68}$. Just 230 cases were

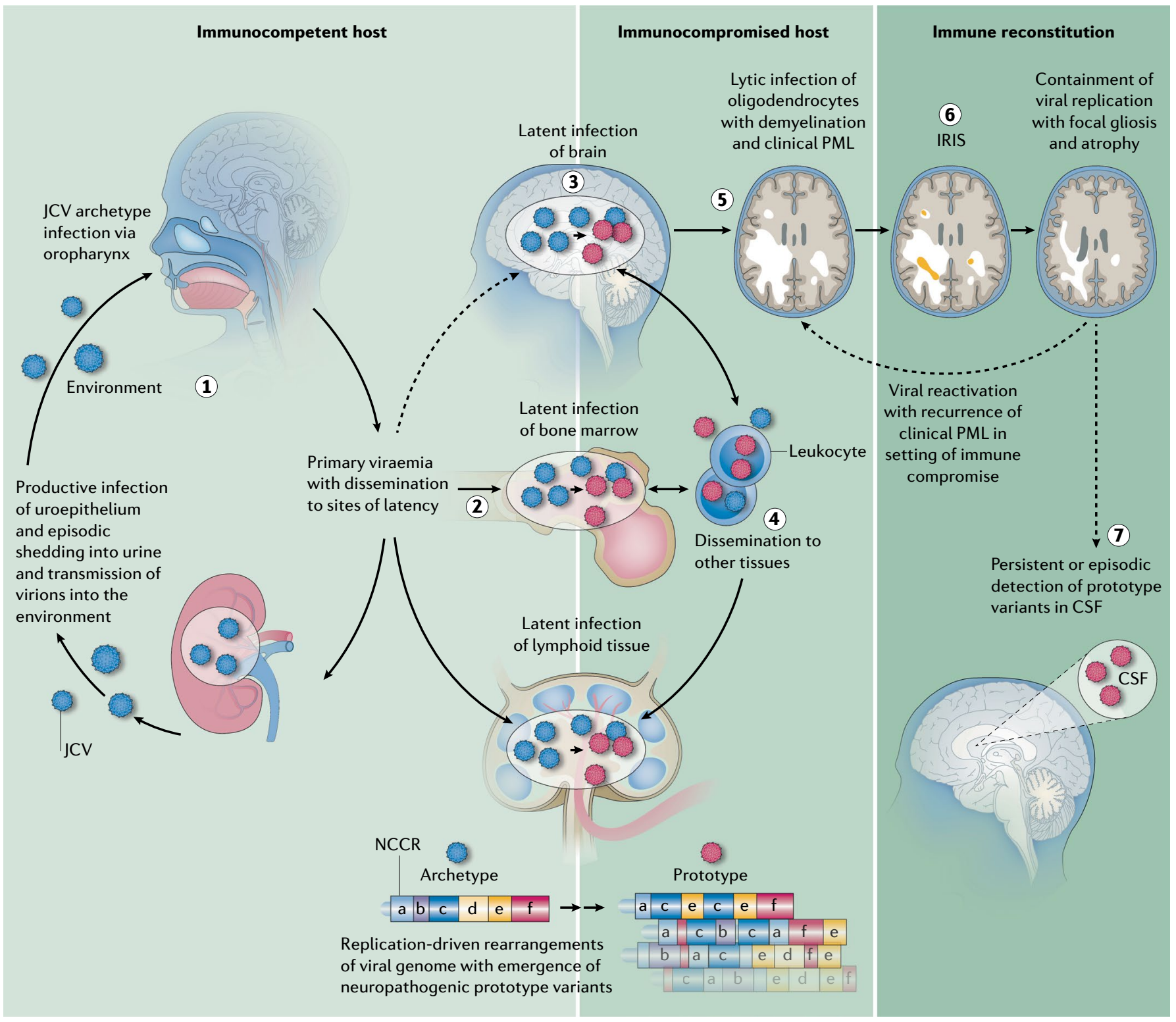

Fig. 2 | Pathophysiology of PML. According to the three-stage model of progressive multifocal leukoencephalopathy (PML) described by Pavlovic et al. ${ }^{63}$, the first stage of infection, which occurs in most of the general population, is subclinical, persistent infection of the kidney with nonpathogenic archetype JC virus (JCV). Shedding of virus into the urine is probably the major source of environmental contamination (step 1). During this stage, the virus can spread to secondary sites, including the bone marrow, lymphoid tissue and possibly the brain, where latent infection can be established (step 2). The second stage of infection can occur with prolonged impairment of cellular immunity, which allows viral reactivation and accumulation of neuropathogenic JCV variants with rearrangements of the non-coding control region (NCCR) (step 3). The anatomic sites of these mutational events are not known. Leukocytes, including $\mathrm{CD} 34^{+}$progenitor cells, B cell lineage cells and other lymphocyte subsets could be vehicles for haematogenous spread of JCV, either via infection of these cells or via passive transportation of virus on the cell surface (step 4). Neurotropic virus might reach the brain at this stage via transportation by leukocytes or as cellfree virus, although local transformation from latent archetype virus has not been excluded. The third stage is clinically manifest PML (step 5). On immune reconstitution, as a result of either specific treatment for PML or discontinuation of an immunosuppressive therapy, subclinical or clinical immune reconstitution inflammatory syndrome (IRIS) can occur (step 6). Patient survival after successful immune reconstitution suggests a fourth stage in which host-virus equilibrium is re-established and latent or persistent infection with rearranged pathogenic virus is established in the brain (step 7). In some patients, low copy numbers of the virus persist in the cerebrospinal fluid (CSF). The risk of PML recurrence in these patients is unknown but it is not negligible. Figure adapted with permission from REF. ${ }^{63}$, Elsevier. 
reported in the literature between 1958 and 1982, more than $60 \%$ of which were associated with underlying lymphoproliferative disease ${ }^{69}$. Haematological malignancy remains an important risk factor - chronic lymphocytic leukaemia and other B cell lineage malignancies are the most common. PML associated with these conditions usually develops in the setting of cytotoxic chemotherapy, stem cell transplantation, total body irradiation or targeted monoclonal antibody therapies, but even untreated haematological malignancy itself causes immune dysfunction, which is associated with a risk of PML. Mortality remains high in this patient population, at $90 \%$ within 2 months ${ }^{70-72}$.

The first report of PML associated with AIDS was published in 1982 (REF. ${ }^{73}$ ). The clinical phenotype seen in HIV-related PML was consistent with that previously reported, but a striking increase in incidence was observed. Between the periods 1980-1984 and 1990-1994, the incidence of PML increased 20-fold, and rates of death from PML peaked in the mid-1990s at 2.76 per million persons $s^{74}$. Before the introduction of cART, the reported prevalence of PML among individuals with HIV was as high as $5-8 \%$. Median survival was 6 months, and just $9 \%$ of patients survived for more than 1 year ${ }^{75}$.

Classic PML can involve supratentorial or infratentorial structures and presents as progressive worsening of multifocal neurological symptoms. Despite rare post-mortem reports of PML affecting the spinal $\operatorname{cord}^{76,77}$, the spinal cord and optic nerves are not affected clinically. Lytic infection of oligodendrocytes leads to expanding areas of demyelination that coalesce over time. The symptoms depend on the locations involved, but the most common include cognitive and behavioural abnormalities, sensory and motor deficits, ataxia, aphasia and cortical visual changes. Seizures occur in $20-44 \%$ of patients over the course of the disease $\mathrm{e}^{78,79}$.

Histopathologically, classic PML is defined by the triad of multifocal demyelination, oligodendroglia with enlarged hyperchromatic nuclei, and enlarged, bizarre astrocytes with irregularly lobulated nuclei ${ }^{64}$. Viral particles are most commonly present in infected oligodendrocytes but in rare cases can be present in astrocytes or even neurons. The viral genome copy number per cell in the brain is $100-1,000$-fold greater than in the kidney ${ }^{69}$.

The typical active PML lesion can be divided into zones. At the leading edge of the lesions are swollen oligodendrocytes that contain viral particles; these oligodendrocytes exhibit loss of some, but not all, myelinassociated proteins but their axons are spared. Few cells are present at the centre of the lesion, and loss of myelin-associated proteins and axons in this region is profound. Phagocytes are present in this area, many of which are engaged in removal of cellular and myelin debris; lymphocytes and plasma cells are rare. The extracellular space is enlarged, and gliotic replacement of normal parenchymal architecture occurs ${ }^{69}$. Importantly, PML involves not only the subcortical white matter and the grey matter-white matter junction but also the cortex and deep grey matter ${ }^{80,81}$, which probably underlies the combination of cortical and subcortical symptoms that are typical of the disease.

MRI - especially T2-weighted sequences, including T2-weighted fluid-attenuated inversion recovery (FLAIR) sequences - is sensitive to PML lesions. At the time of presentation, MRI most commonly reveals multifocal lesions, but repeated MRI can be used to observe asynchronous enlargement and coalescence of lesions and the appearance of new lesions. The typical lesion is hyperintense on T2-weighted FLAIR sequences, involves subcortical and juxtacortical white matter, and usually (but not always) appears sharply delineated at the cortical border. Lesions are isointense or hypointense on T1-weighted images, but the appearance depends heavily on the type of T1-weighted sequence performed. With increasing focal destruction and tissue necrosis, T1-weighted signal intensity decreases, so the overall appearance is highly heterogenous. If the patient survives, neurodegenerative changes with focal atrophy (including ex vacuo dilatation of CSF spaces) can develop over weeks to months. Imaging features commonly associated with inflammation, such as mass effect, are typically absent in classic PML; however,

Table 1 | Summary of diagnostic criteria for PML

\begin{tabular}{|c|c|c|c|c|c|}
\hline \multirow[t]{2}{*}{ Path to diagnosis } & \multirow[t]{2}{*}{ Diagnostic features } & \multicolumn{4}{|l|}{ Diagnosis $^{a}$} \\
\hline & & Definite PML & Probable PML & Possible PML & Not PML \\
\hline \multirow[t]{2}{*}{ Neuropathological } & $\begin{array}{l}\text { Histopathological triad of demyelination, } \\
\text { bizarre astrocytes, and enlarged } \\
\text { oligodendroglial nuclei }\end{array}$ & \multirow{2}{*}{$\begin{array}{l}\text { Histopathological } \\
\text { triad with } \\
\text { detection of JCV } \\
\text { protein and/or } \\
\text { JCV DNA }\end{array}$} & \multirow[t]{2}{*}{$\begin{array}{l}\text { Histopathological } \\
\text { triad only }\end{array}$} & \multirow[t]{2}{*}{$\begin{array}{l}\text { Detection of } \\
\text { JCV protein only }\end{array}$} & \multirow[t]{2}{*}{$\begin{array}{l}\text { No histopathological } \\
\text { evidence of JCV } \\
\text { infection }\end{array}$} \\
\hline & $\begin{array}{l}\text { JCV protein detected in focal brain } \\
\text { lesions by immunohistochemistry or } \\
\text { electron microscopy }\end{array}$ & & & & \\
\hline \multirow{3}{*}{$\begin{array}{l}\text { Combined clinical, } \\
\text { radiological and } \\
\text { laboratory }\end{array}$} & $\begin{array}{l}\text { Clinical: progressive neurological } \\
\text { symptoms }\end{array}$ & \multirow{3}{*}{$\begin{array}{l}\text { JCV DNA } \\
\text { detected in the } \\
\text { CSF, and both } \\
\text { imaging features } \\
\text { and clinical } \\
\text { features present }\end{array}$} & \multirow{3}{*}{$\begin{array}{l}\text { JCV DNA } \\
\text { detected in the } \\
\text { CSF and either } \\
\text { imaging or } \\
\text { clinical features } \\
\text { present }\end{array}$} & \multirow{3}{*}{$\begin{array}{l}\text { Imaging and } \\
\text { clinical features } \\
\text { only, or only } \\
\text { detection of JCV } \\
\text { DNA in the CSF }\end{array}$} & \multirow[t]{3}{*}{$\begin{array}{l}\text { Isolated clinical or } \\
\text { imaging features }\end{array}$} \\
\hline & Imaging: MRI features & & & & \\
\hline & $\begin{array}{l}\text { Laboratory: JCV DNA detected in the } \\
\text { CSF by PCR }\end{array}$ & & & & \\
\hline
\end{tabular}

CSF, cerebrospinal fluid; JCV, JC virus; PCR, polymerase chain reaction; PML, progressive multifocal leukoencephalopathy. ${ }^{a}$ Criteria are compiled from REF. ${ }^{64}$. 


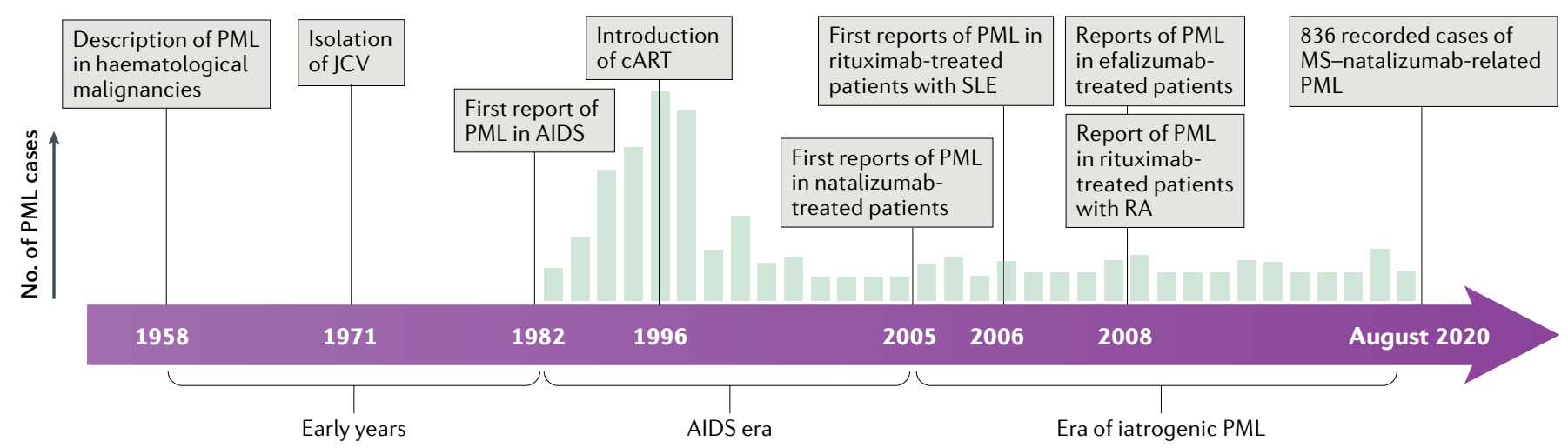

Fig. 3 | Timeline of PML disease eras. From an epidemiological perspective, three distinct eras of progressive multifocal leukoencephalopathy (PML) have been identified. In the early years, following its first description, PML was rare and almost uniformly fatal, seen most commonly in patients with haematological malignancy. During the AIDS pandemic, the incidence of PML increased dramatically - up to $5 \%$ of patients with AIDS developed the disease. With the introduction of combined antiretroviral therapies (cART) in 1996, this proportion declined substantially, and immune reconstitution was established as a way to prevent PML and to increase the chance of survival. Although the majority of PML cases worldwide are still associated with AIDS, iatrogenic PML is linked to a growing number of therapies that target immune function. Most notable of these are natalizumab for the treatment of relapsing-remitting multiple sclerosis (MS), rituximab for the treatment of haematological cancers and rheumatological disorders, and efalizumab for the treatment of psoriasis (efalizumab was withdrawn from the market in 2009 after reports of association with PML). JCV, JC virus; RA, rheumatoid arthritis; SLE, systemic lupus erythematosus.

faint peripheral contrast enhancement was observed in 9\% of patients with HIV-related PML in the pre-cART era, even in the absence of pathologically proven focal inflammatory response ${ }^{82}$. At the leading edges of acutely expanding lesions, restricted diffusion is commonly seen, which is thought to result from swelling of dying oligodendrocytes and astrocytes ${ }^{83}$. A band-like paramagnetic shift and $\mathrm{T} 2{ }^{\star}$ signal change at the grey matter-white matter junction has been observed, possibly corresponding to iron deposition, although the reason for this finding is uncertain ${ }^{84,85}$ (FIG. 4). Cortical and deep grey matter lesions are poorly visualized with MRI.

Inflammatory PML. In addition to reducing the overall incidence of PML among people with HIV, the introduction of cART in the mid-1990s, which enabled functional reversal of immunodeficiency, changed the spectrum of clinical presentations of PML as pathological and radiological inflammatory features began to be described. Importantly, this change was associated with marked increases in survival at 1 year, which reached $\sim 60 \%{ }^{86}$.

With successful immune reconstitution, JCV-specific $\mathrm{CD}^{+}$and $\mathrm{CD}^{+} \mathrm{T}$ cells can be found in the peripheral blood of survivors. Detailed epitope mapping suggests that the JCV capsid protein VP1 induces the strongest immune response. Cellular antiviral immune responses correlate with viral clearance, and the generation of these responses has greater prognostic value for survival than $\mathrm{CD}^{+} \mathrm{T}$ cell counts alone ${ }^{40}$. The role of humoral immune responses in PML is less clear ${ }^{65}$. Paradoxically, a rising level of antibodies to JCV is a validated biomarker of viral reactivation among natalizumab-treated patients with multiple sclerosis, and this measure is used to identify patients in this group who are at the greatest risk of developing $\mathrm{PML}^{87}$.
cART-driven partial or full immune reconstitution can lead to atypical presentations of classic opportunistic infections by triggering a rebound inflammatory response to previously unrecognized or asymptomatic infections. Initially, this phenomenon was called 'immune reconstitution syndrome' ${ }^{\text {'88 }}$ but it was later renamed 'immune reconstitution inflammatory syndrome' (IRIS) ${ }^{89}$. In the context of PML related to HIV infection, IRIS has been defined as immune reconstitution with an increase in $\mathrm{CD} 4^{+} \mathrm{T}$ cell count or a decrease in plasma levels of HIV RNA, combined with sudden worsening of neurological signs and symptoms. Two presentations of IRIS have been described, on the basis of the timing of the clinical manifestations: paradoxical IRIS, in which symptoms of a previously recognized infection worsen, and unmasked IRIS, in which the inflammatory response against subclinical infection renders it clinically manifest. Estimates suggest that $4-42 \%$ of patients with HIV-related PML develop IRIS ${ }^{84,86,90-93}$. Clinical manifestations are usually mild, but if the associated inflammatory response is extensive - which most commonly occurs in patients with the sharpest rise in $\mathrm{CD}^{+}{ }^{+} \mathrm{T}$ cell counts - IRIS can be life-threatening; mortality is $5-28 \%^{86,94-96}$. In general, the development of inflammatory features in PML is thought to be associated with higher survival rates ${ }^{96,97}$, although some reports suggest that this is not always the case $\mathrm{e}^{92}$.

Clinical immune reconstitution is commonly associated with distinct MRI findings that reflect inflammatory changes, including contrast enhancement within the PML lesion (56-87\%), oedema (30\%) and mass effect $(24 \%)^{86,98,99}$; these features are rare in classic PML (seen in $<3 \%$ of patients $)^{96}$. These MRI features probably have limited sensitivity for detection of inflammation, and contrast enhancement is not always seen on MRI, even in pathologically confirmed inflammatory $\mathrm{PML}^{86,100}$. Magnetic resonance spectroscopy ${ }^{101}$, MRI arterial spin 

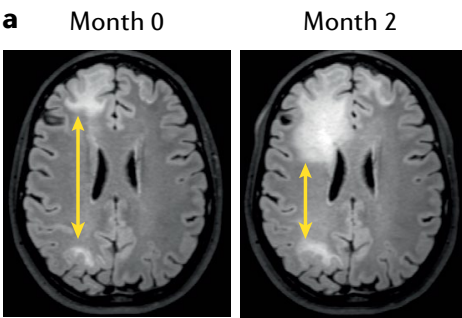

T2-weighted FLAIR images

b

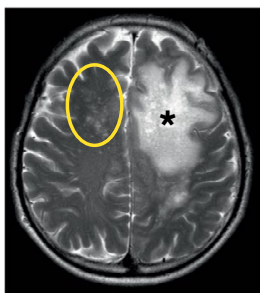

T2-weighted image

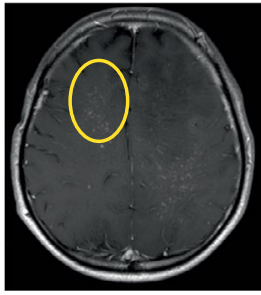

Post-gadolinium T1-weighted image
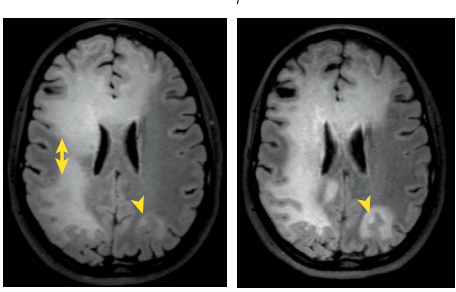

c

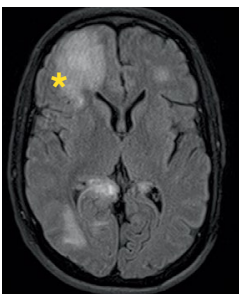

T2-weighted image
Month 4

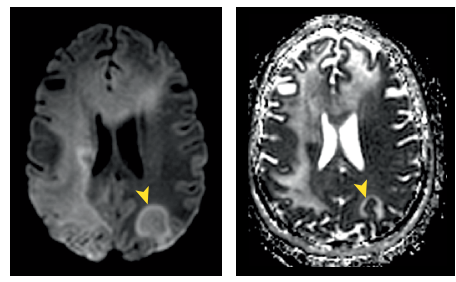

Diffusion-weighted Apparent diffusion image d Month 0
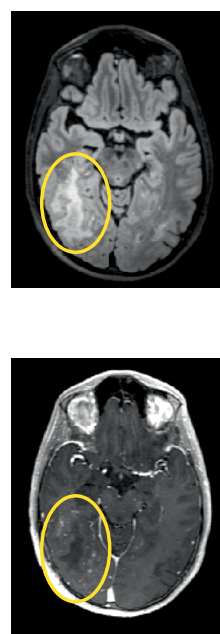

Month 2

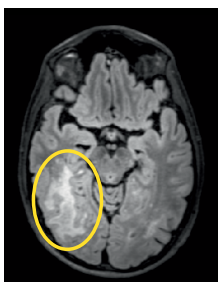

Month 3

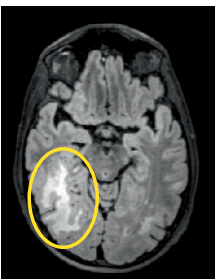

Month 4

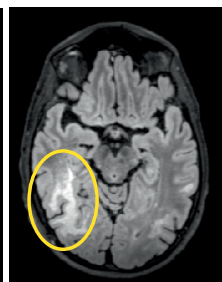

T2-weighted FLAIR images
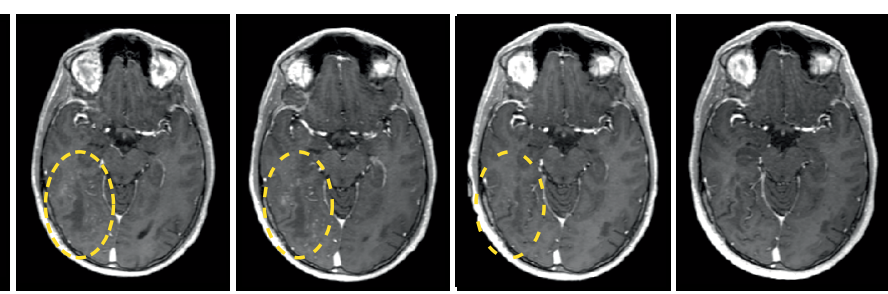

Month 5

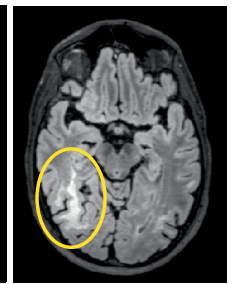

e

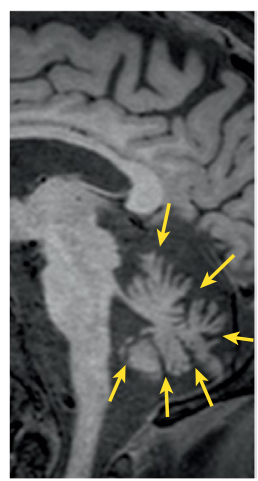

Post-gadolinium T1-weighted images

Fig. 4 | MRI findings in various presentations of JC virus infection. a | MRI of a 40-year-old woman with a history of follicular lymphoma who was treated with bendamustine and rituximab and developed progressive multifocal leukoencephalopathy (PML) while receiving rituximab maintenance therapy. MRI shows progression of PML lesions over a 4-month period. T2-weighted fluid-attenuated inversion recovery (FLAIR) images show enlargement of lesions in the right frontal and parietal lobes (double-headed arrows). At the final time point (month 4), involvement of the right cerebral hemisphere is nearly complete and involvement of the left frontal and parietal lobes is substantial. Mild diffusion restriction (arrow heads) can be seen as hyperintensity on the diffusion-weighted image and as relative hypointensity on the apparent diffusion coefficient map, at the edge of the lesion near the right lateral ventricle and, to a lesser extent, in the left parietal lobe. $\mathbf{b} \mid$ MRI of a 42-year-old man with HIV-related PML after initiation of treatment with antiretroviral therapy. The 'Milky Way' appearance, an MRI feature first described in natalizumab-related PML but that can generally be observed in inflammatory PML, is apparent in these T2-weighted and post-gadolinium T1-weighted images, which show punctate foci of signal abnormality (circled) in addition to the large, non-enhanced lesion in the left frontal lobe (asterisk). c| MRI of a 61-year-old man with HIV-related PML who developed immune reconstitution inflammatory syndrome (IRIS) after initiation of treatment with antiretroviral therapy. MRI shows oedematous lesions in the right frontal lobe and corpus callosum (asterisks). $\mathbf{d}$ | MRI of a 34-year-old man with idiopathic lymphopenia. MRI shows shrinkage of a right temporal lobe lesion over 5 months after successful immune reconstitution with checkpoint inhibition. T2-weighted FLAIR images show reduction in the lesion size (top row, circled) and post-gadolinium T1-weighed images show gradual resolution of contrast enhancement (dashed rings), although resolution of contrast enhancement does not indicate resolution of the lesion. e | MRI of a 60-year-old man with HIV and JC virus granule cell neuronopathy. T1-weighted MRI shows hallmark profound cerebellar atrophy (arrows). 
labelling ${ }^{102}$ and ${ }^{18} \mathrm{~F}$-fluorodeoxyglucose $\mathrm{PET}^{103}$ have been proposed as more sensitive tools for imaging of active inflammation.

Pathologically, inflammatory features in PML are most prominent in PML IRIS, in which a robust perivascular lymphocytic inflammatory infiltrate with a predominant $\mathrm{CD}^{+} \mathrm{T}$ cell population ${ }^{94}$ is observed. CD20 ${ }^{+}$ $\mathrm{B}$ cells and $\mathrm{CD} 138^{+}$plasma cells are also abundant, whereas the levels of macrophages and microglia are similar to those in classic PML ${ }^{104}$. Notably, PML IRIS is associated with lower numbers of JCV-infected cells than is classic PML, indicating successful reduction of infection $^{104,105}$.

Iatrogenic PML. Iatrogenic PML can present as classic or inflammatory PML, depending on the severity of pharmacological immunosuppression and how readily it can be reversed. The first two descriptions of PML associated with rituximab, a CD20 monoclonal antibody that targets B cells that was approved by the FDA in 1997 (REF. ${ }^{106}$ ), were reported in 2002, both in the context of non-Hodgkin lymphoma. With these early cases, however, the relative contribution of any single drug could not be assessed owing to confounding factors, such as previous and ongoing treatments and co-morbidities, that independently increase the risk of PML. However, in 2005, the first alarming reports of PML developing in otherwise immunocompetent patients marked the beginning of a new era of iatrogenic PML. In that year, three patients who had been treated with the a4 integrin monoclonal antibody natalizumab, which had been approved just the year before for treatment of multiple sclerosis and Crohn disease, developed PML. Cases of PML in patients receiving rituximab for treatment of systemic lupus erythematosus followed, and PML in rheumatoid arthritis was first reported in 2008 (REF. ${ }^{107}$ ).

Now, at least 18 FDA-approved medications carry label warnings for $\mathrm{PML}^{63}$. Generally, the risk of PML with these medications is very low, with the exceptions of natalizumab (overall risk of 1 in 1,000$)^{108}$ and the CD11a monoclonal antibody efalizumab (estimated overall risk of 1 in 400); the latter has since been withdrawn from the market ${ }^{109}$. Both of these drugs affect lymphocyte trafficking but are not otherwise immunosuppressive, and the risk of PML with both of these drugs is associated with prolonged exposure of more than 2 years. Taken together, these characteristics make these monoclonal antibody therapies substantially different from historically recognized risk factors for PML. Efalizumab was withdrawn from the market in 2009 after four reported cases of PML. Natalizumab was briefly withdrawn in 2005 following the first reports of PML but was reintroduced in 2006 for treatment of multiple sclerosis under a rigorous pharmacovigilance programme (the TOUCH programme, Biogen Idec). Nevertheless, the number of multiple sclerosis-natalizumab-associated cases of PML continues to rise and had reached 836 by August 2020 (information available on request from Biogen Medical Information). Importantly, these numbers include only cases of definite PML. In the post-cART era and among patients with underlying autoimmune disease, the levels of JCV in the CSF are commonly below the limits of assay detection, so unless tissue diagnosis is pursued, these cases do not meet current diagnostic criteria. Therefore, the reported numbers of PML cases are probably underestimations ${ }^{64,110}$.

In the initial imaging studies of natalizumabassociated PML, contrast enhancement of lesions was present at first diagnosis in $\sim 40 \%$ of patients ${ }^{111,112}$. This proportion was distinctly different from that in other settings, an observation that might reflect the unique nature of immune dysregulation induced by natalizumab. The enhancement patterns in these patients have been described as linear, punctate or rim-like ${ }^{113}$. A new MRI feature has also been described in natalizumab-associated PML that is present in $72 \%$ of patients with this condition: small, perilesional T2 hyperintensities that are often enhanced on administration of contrast material, referred to as a 'Milky Way appearance. This appearance has been proposed as an indication of an early immune response in perivascular spaces, perhaps related to foci of active JCV replication $^{114,115}$. Similar MRI findings have since been seen in PML associated with other causes of immune dysregulation, including HIV-related $\mathrm{PML}^{95}$.

In almost all cases of natalizumab-associated PML, PML IRIS occurs to some degree on discontinuation of natalizumab therapy, within days to a few weeks after plasma exchange or immunoabsorption that are often used to accelerate clearance of active drug. Similarly to PML IRIS in HIV, this condition is characterized by contrast enhancement, oedema and mass effect ${ }^{99}$. Survival among patients with natalizumab-associated PML $(\sim 77 \%)$ is higher than that among patients with other forms of PML, reflecting underlying antiviral immunocompetence once immune cell trafficking is restored after treatment discontinuation ${ }^{111}$.

The estimated overall risk of PML in patients who are treated with natalizumab is 1 in 1,000 . However, several factors in combination can identify the patients who are at the greatest risk of PML. These factors include the presence of JCV antibodies, a duration of natalizumab treatment beyond 2 years and prior treatment with immunosuppressive agents. For patients in the highest risk group based on these factors, the estimated incidence is 11.1 cases per 1,000 per year; among patients who are antibody negative and therefore at the lowest risk, the estimated incidence is at most 0.09 cases per 1,000 per year ${ }^{116}$. Empirical evidence that the measurement of JCV antibodies is useful as a screening tool comes from the observation that the incidence of PML among patients who were treated with natalizumab decreased by $\sim 50 \%$ within 18 months after introduction of the JCV antibody assay ${ }^{117}$. The JCV antibody index, based on measurement of antibodies to JCV, is now used in clinical practice as a biomarker for further stratification of patients who are treated with natalizumab and who have not previously received immunosuppressive treatment ${ }^{118}$. In addition, emerging evidence suggests that extended interval dosing of natalizumab (more than 4 weeks) may decrease the risk of PML among patients who are positive for JCV antibodies and/or who have received prior immunosuppression ${ }^{119}$. 
Across patient populations with PML, the success of immune reconstitution as a treatment for PML is limited by the fact that PML is typically diagnosed only when neurological deficits are manifest, by which time even effectively mounting an antiviral immune response might be too late to modify the outcome. The pharmacovigilance programmes used in monitoring natalizumab treatment for multiple sclerosis, including monitoring of the JCV antibody index and frequent brain MRI, have led to an increase in early identification of PML, and even of preclinical, asymptomatic PML ${ }^{120}$. This early detection contributes to the overall better prognosis of natalizumab-related PML compared with other PML categories.

Asymptomatic PML. In HIV infection, the duration of subclinical PML before its unmasking by antiretroviral therapy is unknown. In natalizumab-treated patients, asymptomatic PML lesions have been retrospectively identified as long as 9 months before the clinical diagnosis ${ }^{121-124}$. In rare cases, PML has been diagnosed at autopsy in patients with no history of neurological disease $^{125}$. Taken together, this evidence supports the concept that PML initially develops more slowly than its rapid end-stage clinical course suggests, potentially offering the opportunity for early diagnosis and intervention.

MRI manifestations of subclinical PML tend to be more localized, involving only a single lobe in $68 \%$ of people; among these, the frontal lobe is most commonly affected (78\%). Inflammation is evident in $40 \%$ of people with subclinical PML, either as contrast-enhanced lesions or the punctate perilesional 'Milky Way' appearance. Up to $40 \%$ of asymptomatic patients seem not to have diffusion restriction at the lesion edge, perhaps indicating limited injury ${ }^{126}$.

Survival after discontinuation of natalizumab treatment is much higher among asymptomatic patients (96\%) than among symptomatic patients $(75 \%)^{127}$. In asymptomatic PML, JCV is often undetected in the CSF, in line with the observation that lower lesion volumes may correlate with low levels of JCV DNA ${ }^{128}$. The inability to detect JCV initially can delay definitive diagnosis and appropriate management, and creates a diagnostic dilemma in the context of current diagnostic criteria, which require detection of the virus ${ }^{129,130}$. Indeed, as many as $20 \%$ of patients monitored in pharmacovigilance programmes who developed confirmed PML had undetected JCV in the CSF at the first diagnostic examination ${ }^{110}$. In this light, the importance of assay sensitivity for improving early diagnosis is evident ${ }^{64}$.

Other JCV-related CNS manifestations. Historically, the clinical manifestations of JCV were thought to be wholly attributed to productive infection of oligodendrocytes and, to a lesser extent, astrocytes, which underlies PML. However, we now know that JCV can infect other CNS cell populations and that infection of these cells can be associated with atypical clinical presentations, such as cerebellar infection, encephalopathy and meningitis.

Lytic infection of cerebellar granule cells causes granule cell neuronopathy (GCN), which leads to focal cell loss in the internal granule cell layer, consequent progressive cerebellar atrophy and the associated clinical syndrome. This condition was first clinically described in HIV-related PML ${ }^{131}$ but has since been identified in a wider range of contexts ${ }^{132-134}$. The hallmark feature of GCN - focal internal granule cell loss - had already been noted in $5 \%$ of the earliest histopathological descriptions of $\mathrm{PML}^{135}$. Both archetype and prototype JCV have been detected in the CSF of patients with GCN. Mutations that affect the carboxy terminus of VP1 have commonly, though not universally, been identified in viral strains associated with GCN, and these mutations have been proposed as a reason for the atypical cellular tropism ${ }^{136,137}$. Radiologically, GCN is characterized by progressive cerebellar atrophy. A mixed clinical picture of GCN associated with classic infratentorial or supratentorial demyelinating PML lesions is not uncommon $^{131,133,136,138}$.

Fulminant encephalopathy secondary to lytic JCV infection of cortical pyramidal neurons has been reported, both with ${ }^{139}$ and without ${ }^{140}$ focal brain parenchymal lesions. These cases were associated with archetype JCV; a large deletion of the regulatory agnoprotein gene $^{141}$ and a 12 -bp insertion in a non-coding region ${ }^{140}$ might have contributed to the atypical presentations in the reported cases.

Meningitic presentations have been associated with JCV in the CSF in patients with no evidence of classic PML. Whether these cases were related to primary infection or viral reactivation is unclear ${ }^{142-144}$. In one patient who presented with subacute meningitis that led to hydrocephalus with cognitive, gait and urinary dysfunction, post-mortem examination revealed productive infection of the leptomeninges and choroid plexus with archetype $\mathrm{JCV}^{145}$. All cases occurred in the absence of parenchymal white matter lesions seen in classic PML, raising the possibility that JCV could be an under-recognized cause of aseptic meningitis.

Although these less common clinical presentations have been described as distinct entities, their specific histopathological features have also been observed in classic PML. In a post-mortem study, JCV-infected cortical neurons were found in $\sim 50 \%$ of brains from people with PML; in some cases, the infected neurons were distant from the classic demyelinating lesions ${ }^{80}$. Similarly, JCV-infected cerebellar granule cell neurons have been found in up to $79 \%$ of brains from people with $\mathrm{PML}^{132}$, and infected leptomeningeal cells have been found in $29 \%$ of brains from people with $\mathrm{PML}^{146}$. In these studies, infected neurons most commonly expressed $\mathrm{T}$ antigen but not VP1 capsid protein, suggesting abortive or restricted infection that may evade immune detection ${ }^{147}$.

\section{Treatment strategies}

Development of antiviral strategies against JCV has been impeded by the lack of an animal model of PML and difficulties with propagating the virus in culture. Furthermore, the rarity and severity of the disease have posed methodological and ethical obstacles to clinical investigations. For these reasons, investigation of treatments for PML have, for the most part, been limited to small case series, with just five prospective interventional 
studies published in the past 20 years ${ }^{148-151}$. Broadly, two therapeutic strategies have been investigated: direct antiviral therapies and indirect strategies designed to restore antiviral immune responses.

Several strategies for direct antiviral targeting have been attempted. JCV DNA replication has been targeted with the nucleoside analogues cytarabine $e^{148}$ and cidofovir ${ }^{152}$ and with the topoisomerase inhibitor topotecan ${ }^{149}$. Viral entry into glial cells via the $5-\mathrm{HT}_{2 \mathrm{~A}}$ receptor has been targeted with the receptor antagonist mirtazapine ${ }^{153}$. The antimalarial agent mefloquine, which blocks viral infection and replication in vitro, has also been investigated ${ }^{151}$. None of these strategies has convincingly prolonged survival or reduced neurological disability in a clinical trial; indeed, most studies of these approaches were terminated early owing to either a lack of benefit or excessive toxicity ${ }^{148,149,151}$.

Consequently, immune reconstitution remains the most effective strategy for treatment of PML. Success of this strategy depends on early diagnosis, limited disease progression and rapid and effective immune repletion. In its simplest form, immune reconstitution can be accomplished by initiation of cART in HIV-related PML and by discontinuation of immunosuppressive therapy in non-HIV-related disease. In natalizumab-related PML, use of plasma exchange or immunoadsorption is commonly used to accelerate drug clearance, although some evidence suggests that this does not improve outcomes and can be associated with more severe IRIS ${ }^{154,155}$.

For many patient populations, immune reconstitution cannot readily be achieved. An increasing number of strategies have been or are being developed for use in this scenario to promote antiviral immune responses, either definitively or as a bridge until full spontaneous recovery is achieved. Approaches that have been reported anecdotally include recombinant IL-2 (REFS ${ }^{156-159}$ ), filgrastim ${ }^{160}$, IL-7 as monotherapy ${ }^{161-165}$ and active vaccination against JCV VP1 boosted with IL-7 (REF. ${ }^{166}$ ). IL-7, which is critical for the maintenance of $\mathrm{T}$ cell homeostasis, is of particular interest for patients with underlying lymphopenia and a restricted repertoire of $\mathrm{T}$ cell receptors because it preferentially expands recent thymic emigrant populations, naive $\mathrm{T}$ cells and central memory $\mathrm{T}$ cells, thereby increasing $\mathrm{T}$ cell numbers and antiviral activity, the effects of which last long after the treatment is administered ${ }^{167}$.

Some immune reconstitution strategies have been tested in larger numbers of patients and could hold promise. The first of these is the use of checkpoint inhibitors. Persistent viral infections are associated with progressive development of immune exhaustion, which is characterized by a programmed loss of lymphocyte effector functions. Physiologically, this mechanism limits immune-mediated injury in the context of chronic inflammation, but it can impair viral clearance. Checkpoint inhibitors target pathways that are involved in immune exhaustion and can reinvigorate antiviral immunity. Evidence from a total of 18 patients with refractory immunosuppression suggests that targeting programmed cell death protein 1 (PD1) can lead to restoration of anti-JCV activity of $\mathrm{CD}^{+}$and $\mathrm{CD}^{+} \mathrm{T}$ cells and associated clinical and radiological benefit in some patients ${ }^{168}$. This approach seems to be most promising for individuals in whom some anti-JCV cellular immune response is detectable before treatment: in these patients, reinvigoration of antiviral responses was seen after one or two monthly drug administrations. Conversely, advanced PML and profound immune compromise are associated with poor responses to this therapy ${ }^{169}$. Immune-related adverse events have been well documented in oncological applications of checkpoint inhibitors $^{170}$, and such events are likely to emerge among patients who receive this treatment for PML — some of whom have underlying autoimmunity — if checkpoint inhibition is applied more broadly in this disease.

Another promising therapeutic strategy for PML is adoptive immunotherapy with virus-specific $\mathrm{T}$ cells that are generated from related and unrelated donors. This approach has been reported in a total of four patients ${ }^{171,172}$, and a pilot study in 12 patients was completed in $2020\left(\mathrm{REF}^{173}\right)$. Experience with this strategy to date suggests that JCV-specific T cell products, either as off-the-shelf products or generated ad hoc, could be a viable interventional strategy, as seen in other viral infections ${ }^{174,175}$.

All immune reconstitution strategies carry the risk of triggering IRIS. IRIS creates a management dilemma that requires balancing the need to temper inflammatory responses with the risk of PML progression if they are fully suppressed. Although no formal trials have been conducted, case reports suggest that steroids can control overexuberant inflammation in some patients ${ }^{98}$. However, steroids affect antiviral responses ${ }^{176}$ and are, therefore, not recommended for preventive use but should be reserved for instances in which the inflammation itself might compromise the patient's outcome ${ }^{177-179}$. Alternatively, CCR5 ${ }^{+} \mathrm{T}$ cells, which have a prominent role in IRIS, could be directly targeted. On this basis, the CCR5 antagonist maraviroc has been used to selectively limit trafficking of these cells into the CNS, but results have been mixed, so whether this approach will be of benefit is unclear ${ }^{180-184}$.

\section{After PML}

Little has been published about long-term survivors of PML. Among survivors of HIV-related PML, 44-83\% achieve clinical stabilization or some improvement if cART is initiated early in the disease course ${ }^{185}$. Similarly, a shorter time to diagnosis and more localized disease are associated with better functional outcomes in natalizumab-related $\mathrm{PML}^{186}$. However, many long-term survivors are left with substantial morbidity - almost $70 \%$ experience some residual neurological disability that is moderate to severe in $25-50 \%{ }^{185,187}$. Up to $44 \%$ of survivors experience seizures ${ }^{79}$.

In follow-up studies of people who survived PML, persistence of JCV in the CSF has been detected for as long as 3 years ${ }^{65,188,189}$. Similarly, post-mortem studies have revealed persistence of JCV DNA in the brains of longterm survivors of HIV-related PML and natalizumabrelated $\mathrm{PML}^{66,190,191}$. This evidence suggests that, despite immune reconstitution and clinical stabilization, JCV is not always cleared from the CNS but can instead return to a state of latency or persistent infection. 
The risk of recurrence of PML is unknown, but rare cases of recurrence have been reported in HIV-related PML years after the initial presentation and despite continued cART and HIV suppression ${ }^{67}$. In natalizumabrelated PML and other drug-related PML, this risk creates a dilemma in the subsequent management of the underlying predisposing disease - most often cancer, multiple sclerosis or another chronic inflammatory illness - because reinitiation of immunosuppression could conceivably lead to viral reactivation and possibly recurrence of PML. In one longitudinal study of 23 people who survived natalizumab-related PML, no recurrence of PML was seen on reinstitution of disease-modifying therapies, including dimethyl fumarate and fingolimod, each of which has been independently associated with isolated cases of PML ${ }^{192-194}$.

\section{Conclusions and future perspectives}

Much has been learned about PML over the past decades, and this knowledge has led to the development of promising treatment strategies. However, the disease remains a serious threat, particularly as use of immunosuppressive therapies increases for a variety of diseases, and many unanswered questions about its pathobiology remain. Resolution of these questions could lead to the discovery of new therapeutic targets. Further validation of imaging and laboratory biomarkers for monitoring of patients who are at risk of developing PML could also help to prevent PML or enable earlier detection of the disease in susceptible patient populations to improve outcomes, as has been seen in natalizumab-related PML.

Developing more effective strategies for boosting antiviral immune responses and optimizing the application of these strategies will be of great importance. Indeed, indiscriminate boosting of immune responses might not be effective in some populations, such as those with severe bone marrow depression or genetic $\mathrm{T}$ cell dysfunction, and could be too risky in others, such as those with systemic inflammatory diseases that affect vital organs. In such patient populations, adoptive transfer of virus-specific $\mathrm{T}$ cells could be a better option. These cells could be generated ex vivo by use of viral peptide libraries or could be genetically engineered to express $\mathrm{T}$ cell receptors that specifically target immunodominant viral antigens.

Nevertheless, the ultimate goal remains the identification of effective antiviral agents. In this context, advances in gene therapy that enable direct targeting of the viral genome could provide powerful tools. In addition, clinical research is needed with a focus on the increasing number of people who survive PML; issues that need to be addressed include optimization of functional outcomes, persistent infection and the risk of PML recurrence.

Published online 20 November 2020
1. Padgett, B. L., Walker, D. L., ZuRhein, G. M., Eckroade, R. J. \& Dessel, B. H. Cultivation of papova-like virus from human brain with progressive multifocal leucoencephalopathy. Lancet 1, 1257-1260 (1971).

2. Moens, U. et al. Biology, evolution, and medical importance of polyomaviruses: an update. Infect. Genet. Evol. 54, 18-38 (2017).

3. White, M. K., Gordon, J. \& Khalili, K. The rapidly expanding family of human polyomaviruses: recent developments in understanding their life cycle and role in human pathology. PLoS Pathog. 9, e1003206 (2013).

4. Buck, C. B. et al. The ancient evolutionary history of polyomaviruses. PLoS Pathog. 12, e 1005574 (2016)

5. Kajān, G. L., Doszpoly, A., Tarjān, Z. L., Vidovszky, M. Z. $\&$ Papp, T. Virus-host coevolution with a focus on animal and human DNA viruses. J. Mol. Evol. 88, 41-56 (2020).

6. Zheng, H.-Y., Kitamura, T., Takasaka, T., Chen, Q. $\delta$ Yogo, Y. Unambiguous identification of JC polyomavirus strains transmitted from parents to children. Arch. Virol. 149, 261-273 (2004).

7. Knowles, W. A. et al. Population-based study of antibody to the human polyomaviruses BKV and JCV and the simian polyomavirus SV40. J. Med. Virol. 71, 115-123 (2003)

8. Kean, J. M., Rao, S., Wang, M. \& Garcea, R. L. Seroepidemiology of human polyomaviruses. PLOS Pathog. 5, e1000363 (2009).

9. Egli, A. et al. Prevalence of polyomavirus BK and JC infection and replication in 400 healthy blood donors. J. Infect. Dis. 199, 837-846 (2009).

10. Hennes, E. M. et al. Age-dependent seroprevalence of JCV antibody in children. Neuropediatrics 47. 112-114 (2016)

11. Moens, U., Van Ghelue, M., Song, X. \& Ehlers, B. Serological cross-reactivity between human polyomaviruses. Rev. Med. Virol. 23, 250-264 (2013).

12. Bofill-Mas, S. \& Girones, R. Role of the environment in the transmission of JC virus. J. Neurovirol. 9 54-58 (2003).

13. Hirsch, H. H. et al. European perspective on human polyomavirus infection, replication and disease in solid organ transplantation. Clin. Microbiol. Infect. 20 74-88 (2014)

14. Monaco, M. C., Jensen, P. N., Hou, J., Durham, L. C. \& Major, E. O. Detection of JC virus DNA in human tonsil tissue: evidence for site of initial viral infection J. Virol. 72, 9918-9923 (1998).

15. Bofill-Mas, S., Formiga-Cruz, M., Clemente-Casares, P., Calafell, F. \& Girones, R. Potential transmission of human polyomaviruses through the gastrointestinal tract after exposure to virions or viral DNA. J. Virol. 75, 10290-10299 (2001).

16. Monaco, M. C., Atwood, W. J., Gravell, M. Tornatore, C. S. \& Major, E. O. JC virus infection of hematopoietic progenitor cells, primary B lymphocytes, and tonsillar stromal cells: implications for viral latency. J. Virol. 70, 7004-7012 (1996).

17. White, M. K. \& Khalili, K. Pathogenesis of progressive multifocal leukoencephalopathy-revisited. J. Infect. Dis. 203, 578-586 (2011).

18. Bofill-Mas, S., Pina, S. \& Girones, R. Documenting the epidemiologic patterns of polyomaviruses in human populations by studying their presence in urban sewage. Appl. Env. Microbiol. 66, 238-245 (2000).

19. Kitamura, T. et al. Persistent JC virus (JCV) infection is demonstrated by continuous shedding of the same JCV strains. J. Clin. Microbiol. 35, 1255-1257 (1997).

20. Wollebo, H. S., White, M. K., Gordon, J., Berger, J. R. $\&$ Khalili, K. Persistence and pathogenesis of the neurotropic polyomavirus JC. Ann. Neurol. 77, 560-570 (2015)

21. Pietropaolo, V., Prezioso, C., Bagnato, F. \& Antonelli, G. John Cunningham virus: an overview on biology and disease of the etiological agent of the progressive multifocal leukoencephalopathy. New Microbiol. 41 , 179-186 (2018)

22. Sabath, B. F. \& Major, E. O. Traffic of JC virus from sites of initial infection to the brain: the path to progressive multifocal leukoencephalopathy. J. Infect Dis. 186, S180-S186 (2002)

23. Marshall, L. J. \& Major, E. O. Molecular regulation of JC virus tropism: insights into potential therapeutic targets for progressive multifocal leukoencephalopathy. J. Neuroimmune Pharmacol. 5, 404-417 (2010).

24. Ferenczy, M. W. et al. Molecular biology, epidemiology, and pathogenesis of progressive multifocal leukoencephalopathy, the JC virus-induced demyelinating disease of the human brain. Clin. Microbiol. Rev. 25, 471-506 (2012).

25. Monaco, M. C., Sabath, B. F., Durham, L. C. $\&$ Major, E. O. JC virus multiplication in human hematopoietic progenitor cells requires the NF-1 class D transcription factor. J. Virol. 75, 9687-9695 (2001).
26. Yogo, Y. et al. Isolation of a possible archetypal JC virus DNA sequence from nonimmunocompromised individuals. J. Virol. 64, 3139-3143 (1990).

27. Daniel, A. M., Swenson, J. J., Mayreddy, R. P., Khalili, K. $\&$ Frisque, R. J. Sequences within the early and late promoters of archetype JC virus restrict viral DNA replication and infectivity. Virology 216, 90-101 (1996).

28. Van Loy, T. et al. JC virus quasispecies analysis reveals a complex viral population underlying progressive multifocal leukoencephalopathy and supports viral dissemination via the hematogenous route. J. Virol. 89, 1340-1347 (2015).

29. Agostini, H. T. et al. Genotypes of JC virus in east central and southwest Europe. J. Gen. Virol. 82, 1221-1331 (2001).

30. Ault, G. S. \& Stoner, G. L. Human polyomavirus JC promoter/enhancer rearrangement patterns from progressive multifocal leukoencephalopathy brain are unique derivatives of a single archetypal structure. J. Gen. Virol. 74, 1499-1507 (1993).

31. Gosert, R., Kardas, P., Major, E. O. \& Hirsch, H. H. Rearranged JC virus noncoding control regions found in progressive multifocal leukoencephalopathy patient samples increase virus early gene expression and replication rate. J. Virol. 84, 10448-10456 (2010).

32. Johnson, $\mathrm{E}, \mathrm{M}$ et al in the context of immunosuppression: a series of adaptive, DNA replicationdriven recombination events in the development of progressive multifocal leukoencephalopathy. Clin. Dev. Immunol. 2013, 197807-197810 (2013).

33. L'Honneur, A.-S. et al. Exploring the role of NCCR variation on $\mathrm{JC}$ polyomavirus expression from dual reporter minicircles. PLoS One 13, e0199171 (2018)

34. Nakamichi, K. et al. Sequential changes in the noncoding control region sequences of JC polyomaviruses from the cerebrospinal fluid of patients with progressive multifocal leukoencephalopathy. Arch. Virol. 158, 639-650 (2013)

35. Yogo, Y. et al. JC virus regulatory region rearrangements in the brain of a long surviving patient with progressive multifocal leukoencephalopathy. J. Neurol. Neurosurg. Psychiatry 71, 397-400 (2001).

36. Yasuda, Y. et al. Comparison of PCR-amplified JC virus control region sequences from multiple brain regions in PML. Neurology 61, 1617-1619 (2003). 
37. Ferrante, P. et al. PCR detection of JC virus DNA in brain tissue from patients with and without progressive multifocal leukoencephalopathy. J. Med. Virol. 47, 219-225 (1995).

38. Delbue, S. et al. Presence and expression of JCV early gene large $\mathrm{T}$ Antigen in the brains of immunocompromised and immunocompetent individuals. J. Med. Virol. 80, 2147-2152 (2008).

39. White, F. A., Ishaq, M., Stoner, G. L. \& Frisque, R. J. $J C$ virus DNA is present in many human brain samples from patients without progressive multifocal leukoencephalopathy. J. Virol. 66, 5726-5734 (1992).

40. Tan, C. S. et al. JC virus latency in the brain and extraneural organs of patients with and without progressive multifocal leukoencephalopathy. J. Virol. 84, 9200-9209 (2010)

41. Chalkias, S. et al. JC virus reactivation during prolonged natalizumab monotherapy for multiple sclerosis. Ann. Neurol. 75, 925-934 (2014).

42. Dubois, V. et al. Latency and reactivation of JC virus in peripheral blood of human immunodeficiency virus type 1 -infected patients. J. Clin. Microbiol. 35, 2288-2292 (1997)

43. Pasquier, Du. R. A. et al. A prospective study demonstrates an association between JC virus-specific cytotoxic T lymphocytes and the early control of progressive multifocal leukoencephalopathy. Brain 127, 1970-1978 (2004)

44. Gheuens, S. et al. Role of CD4 ${ }^{+}$and CD8 ${ }^{+}$T-cell responses against $\mathrm{JC}$ virus in the outcome of patients with progressive multifocal leukoencephalopathy (PML) and PML with immune reconstitution inflammatory syndrome. J. Virol. 85, 7256-7263 (2011).

45. Khanna, N., Wolbers, M., Mueller, N. J., Garzoni, C., Pasquier, Du. R. A. \& Fux, C. A. et al. JC virus-specific immune responses in human immunodeficiency virus type 1 patients with progressive multifoca leukoencephalopathy. J. Virol. 83, 4404-4411 (2009).

46. Tan, C. S. et al. Immune reconstitution after allogeneic hematopoietic stem cell transplantation is associated with selective control of JC virus reactivation. Biol. Blood Marrow Transpl. 20, 992-999 (2014).

47. Wittmann, T. et al. JC polyomavirus reactivation is common following allogeneic stem cell transplantation and its preemptive detection may prevent lethal complications. Bone Marrow Transpl. 50, 984-991 (2015).

48. Chen, Y. et al. Asymptomatic reactivation of JC virus in patients treated with natalizumab. N. Engl. J. Med. 361, 1067-1074 (2009)

49. Pietropaolo, V. et al. Human polyomavirus JC replication and non-coding control region analysis in multiple sclerosis patients under natalizumab treatment. J. Neurovirol. 21, 653-665 (2015).

50. Bellizzi, A. et al. Polyomavirus JC reactivation and noncoding control region sequence analysis in pediatric Crohn's disease patients treated with infliximab. J. Neurovirol 17, 303-313 (2011).

51. Zheng, H.-Y. et al. New sequence polymorphisms in the outer loops of the JC polyomavirus major capsid protein (VP1) possibly associated with progressive multifocal leukoencephalopathy. J. Gen. Virol. 86 2035-2045 (2005).

52. Delbue, $\mathrm{S}$. et al. JC virus VP1 loop-specific polymorphisms are associated with favorable prognosis for progressive multifocal leukoencephalopathy. J. Neurovirol 15, 51-56 (2009)

53. Sunyaev, S. R., Lugovskoy, A., Simon, K. \& Gorelik, L. Adaptive mutations in the JC virus protein capsid are associated with progressive multifocal leukoencephalopathy (PML). PLoS Genet. 5 , e1000368 (2009).

54. Gorelik, L. et al. Progressive multifocal leukoencephalopathy (PML) development is associated with mutations in JC virus capsid protein VP1 that change its receptor specificity. J. Infect. Dis. 204, 103-114 (2011).

55. Jelcic, I. et al. T cell epitope mapping of JC polyoma virus-encoded proteome reveals reduced $\mathrm{T}$ cell responses in HLA-DRB $1 * 04: 01^{+}$donors. J. Virol. 87 3393-3408 (2013)

56. Power, C. et al. AIDS- and non-AIDS-related PML association with distinct p53 polymorphism. Neurology 54, 743-746 (2000).

57. Eis, P. S. et al. Germline genetic risk variants for progressive multifocal leukoencephalopathy. Front. Neurol. 11, 186 (2020)

58. Tada, H. et al. Trans-activation of the JC virus late promoter by the tat protein of type 1 human immunodeficiency virus in glial cells. Proc. Natl Acad. Sci. USA 87, 3479-3483 (1990).

59. Daniel, D. C. et al. Internalization of exogenous human immunodeficiency virus-1 protein, Tat, by KG-1 oligodendroglioma cells followed by stimulation of DNA replication initiated at the JC virus origin. DNA Cell Biol. 23, 858-867 (2004).

60. Marshall, L. J., Dunham, L. \& Major, E. O. Transcription factor Spi-B binds unique sequences present in the tandem repeat promoter/enhancer of JC virus and supports viral activity. J. Gen. Virol. 91, 3042-3052 (2010).

61. Marshall, L. J. et al. Lymphocyte gene expression and $\mathrm{JC}$ virus noncoding control region sequences are linked with the risk of progressive multifocal leukoencephalopathy. J. Virol. 88, 5177-5183 (2014).

62. Frohman, E. M. et al. JC virus in $\mathrm{CD}_{34} 4^{+}$and $\mathrm{CD} 19^{+}$ cells in patients with multiple sclerosis treated with natalizumab. JAMA Neurol. 71, 596-602 (2014).

63. Pavlovic, D., Patel, M. A., Patera, A. C. \& Peterson, I., Progressive Multifocal Leukoencephalopathy Consortium. T cell deficiencies as a common risk factor for drug associated progressive multifocal leukoencephalopathy. Immunobiology 223, 508-517 (2018).

64. Berger, J. R. et al. PML diagnostic criteria: consensus statement from the AAN Neuroinfectious Disease Section. Neurology 80, 1430-1438 (2013).

65. Ryschkewitsch, C. F., Jensen, P. N., Monaco, M. C. $\&$ Major, E. O. JC virus persistence following progressive multifocal leukoencephalopathy in multiple sclerosis patients treated with natalizumab. Ann. Neurol. 68, 384-391 (2010).

66. Himedan, M. et al. Pathologic findings of chronic PMLIRIS in a patient with prolonged PML survival following natalizumab treatment. J. Investig. Med. High Impact Case Rep. 5, 2324709617734248 (2017).

67. Crossley, K. M. et al. Recurrence of progressive multifocal leukoencephalopathy despite immune recovery in two HIV seropositive individuals. J. Neurovirol. 22, 541-545 (2016).

68. Astrom, K. E., Mancall, E. L. \& Richardson, E. P. Progressive multifocal leuko-encephalopathy; a hitherto unrecognized complication of chronic lymphatic leukaemia and Hodgkin's disease. Brain 81, 93-111 (1958).

69. Brooks, B. R. \& Walker, D. L. Progressive multifocal leukoencephalopathy. Neurol. Clin. 2, 299-313 (1984).

70. Carson, K. R. et al. Progressive multifocal leukoencephalopathy associated with brentuximab vedotin therapy: a report of 5 cases from the Southern Network on Adverse Reactions (SONAR) project. Cancer 120, 2464-2471 (2014).

71. Pavlovic, D., Patera, A. C., Nyberg, F., Gerber, M. \& Liu, M. Progressive multifocal leukeoncephalopathy consortium. progressive multifocal leukoencephalopathy: current treatment options and future perspectives. Ther. Adv. Neurol. Disord. 8, 255-273 (2015).

72. Sano, Y. et al. Rituximab-associated progressive multifocal leukoencephalopathy derived from nonHodgkin lymphoma: neuropathological findings and results of mefloquine treatment. Intern. Med. $\mathbf{5 4}$ 965-970 (2015)

73. Miller, J. R. et al. Progressive multifocal leukoencaphalopathy in a male homosexual with T-cell immune deficiency. N. Engl. J. Med. 307, 1436-1438 (1982)

74. Christensen, K. L. Y., Holman, R. C., Hammett, T. A. Belay, E. D. \& Schonberger, L. B. Progressive multifocal leukoencephalopathy deaths in the USA, 1979-2005. Neuroepidemiology 35, 178-184 (2010).

75. Berger, J. R., Pall, L., Lanska, D. \& Whiteman, M. Progressive multifocal leukoencephalopathy in patients with HIV infection. J. Neurovirol. 4, 59-68 (1998).

76. Bernal-Cano, F., Joseph, J. T. \& Koralnik, I. J. Spinal cord lesions of progressive multifocal leukoencephalopathy in an acquired immunodeficiency syndrome patient. J. Neurovirol. 13, 474-476 (2007).

77. Takeda, S. et al. Progressive multifocal leukoencephalopathy showing extensive spinal cord involvement in a patient with lymphocytopenia. Neuropathology 29, 485-493 (2009).

78. Bartsch, T. et al. The spectrum of progressive multifocal leukoencephalopathy: a practical approach. Eur. J. Neurol. 26, 566-e41 (2019).

79. Miskin, D. P., Herman, S. T., Ngo, L. H. \& Koralnik, I. J. Predictors and characteristics of seizures in survivors of progressive multifocal leukoencephalopathy. J. Neurovirol. 22, 464-471 (2016).
80. Wuthrich, C. \& Koralnik, I. J. Frequent infection of cortical neurons by JC virus in patients with progressive multifocal leukoencephalopathy. J. Neuropathol. Exp. Neurol. 71, 54-65 (2012).

81. Ono, D. et al. Development of demyelinating lesions in progressive multifocal leukoencephalopathy (PML): comparison of magnetic resonance images and neuropathology of post-mortem brain. Neuropathology 39, 294-306 (2019)

82. Whiteman, M. L. et al. Progressive multifocal leukoencephalopathy in $47 \mathrm{HIV}$-seropositive patients: neuroimaging with clinical and pathologic correlation. Radiology 187, 233-240 (1993).

83. Bergui, M. et al. Progressive multifocal leukoencephalopathy: diffusion-weighted imaging and pathological correlations. Neuroradiology 46, 22-25 (2004).

84. Miyagawa, M. et al. Low signal intensity in U-fiber identified by susceptibility-weighted imaging in two cases of progressive multifocal leukoencephalopathy. J. Neurol. Sci. 344, 198-202 (2014).

85. Thurnher, M. M., Boban, J., Rieger, A. \& Gelpi, E. Susceptibility-weighted MR imaging hypointense rim in progressive multifocal leukoencephalopathy: the end point of neuroinflammation and a potential outcome predictor. Am. J. Neuroradiol. 40, 994-1000 (2019).

86. Fournier, A. et al. Immune reconstitution inflammatory syndrome unmasking or worsening AIDS-related progressive multifocal leukoencephalopathy: a literature review. Front. Immunol. 8, 577 (2017).

87. Warnke, C. et al. Cerebrospinal fluid JC virus antibody index for diagnosis of natalizumab-associated progressive multifocal leukoencephalopathy. Ann. Neurol. 76, 792-801 (2014)

88. Behrens, G. M., Meyer, D., Stoll, M. \& Schmidt, R. E. Immune reconstitution syndromes in human immunodeficiency virus infection following effective antiretroviral therapy. Immunobiology 202, 186-193 (2000).

89. Shelburne, S. A. et al. Immune reconstitution inflammatory syndrome: emergence of a unique syndrome during highly active antiretroviral therapy. Medicine 81, 213-227 (2002).

90. Engsig, F. N. et al. Incidence, clinical presentation, and outcome of progressive multifocal leukoencephalopathy in HIV-infected patients during the highly active antiretroviral therapy era: a nationwide cohort study. J. Infect. Dis. 199, 77-83 (2009).

91. Falcó, V. et al. Influence of HAART on the clinical course of HIV-1-infected patients with progressive multifocal leukoencephalopathy: results of an observational multicenter study. J. Acquir. Immune Defic. Syndr. 49, 26-31 (2008).

92. Summers, N. A., Kelley, C. F., Armstrong, W. Marconi, V. C. \& Nguyen, M. L. Not a disease of the past: a case series of progressive multifocal leukoencephalopathy in the established antiretroviral Era. AIDS Res. Hum. Retroviruses 35, 544-552 (2019).

93. Müller, M. et al. Immune reconstitution inflammatory syndrome in patients starting antiretroviral therapy for HIV infection: a systematic review and meta-analysis. Lancet Infect. Dis. 10, 251-261 (2010).

94. Vendrely, A. et al. Fulminant inflammatory leukoencephalopathy associated with HAART-induced immune restoration in AIDS-related progressive multifocal leukoencephalopathy. Acta Neuropathol. 109, 449-455 (2005)

95. Post, M. J. D. et al. CNS-immune reconstitution inflammatory syndrome in the setting of HIV infection, part 1: overview and discussion of progressive multifocal leukoencephalopathy-immune reconstitution inflammatory syndrome and cryptococcal-immune reconstitution inflammatory syndrome. $\mathrm{Am}$. J. Neuroradiol. 34, 1297-1307 (2013).

96. Sainz-de-la-Maza, S. et al. Incidence and prognosis of immune reconstitution inflammatory syndrome in HIV-associated progressive multifocal leucoencephalopathy. Eur. J. Neurol. 23, 919-925 (2016).

97. Berger, J. R., Levy, R. M., Flomenhoft, D. ¿ Dobbs, M Predictive factors for prolonged survival in acquired immunodeficiency syndrome-associated progressive multifocal leukoencephalopathy. Ann. Neurol. 44 341-349 (1998)

98. Tan, K., Roda, R., Ostrow, L., McArthur, J. \& Nath, A. PML-IRIS in patients with HIV infection: clinical manifestations and treatment with steroids. Neurology 72, 1458-1464 (2009).

99. Tan, I. L., McArthur, J. C., Clifford, D. B., Major, E. O. $\&$ Nath, A. Immune reconstitution inflammatory syndrome in natalizumab-associated PML. Neurology 77, 1061-1067 (2011) 
100. Huang, D. et al. Inflammatory progressive multifocal leukoencephalopathy in human immunodeficiency virus-negative patients. Ann. Neurol. 62, 34-39 (2007).

101. Gheuens, S. et al. Metabolic profile of PML lesions in patients with and without IRIS: an observational study. Neurology 79, 1041-1048 (2012).

102. Khoury, M. S. et al. Hyperperfusion in progressive multifocal leukoencephalopathy is associated with disease progression and absence of immune reconstitution inflammatory syndrome. Brain 136 3441-3450 (2013)

103. Baheerathan, A. et al. The utility of FDG-PET imaging in distinguishing PML-IRIS from PML in a patient treated with natalizumab. Neurology 91, 572-573 (2018).

104. Bauer, J., Gold, R., Adams, O. \& Lassmann, H. Progressive multifocal leukoencephalopathy and immune reconstitution inflammatory syndrome (IRIS). Acta Neuropathol. 130, 751-764 (2015).

105. Martin-Blondel, G. et al. In situ evidence of JC virus control by CD8T cells in PML-IRIS during HIV infection. Neurology 81, 964-970 (2013).

106. Berger, J. R., Malik, V., Lacey, S., Brunetta, P. \& Lehane, P. B. Progressive multifocal leukoencephalopathy in rituximab-treated rheumatic diseases: a rare event. J. Neurovirol. 24, 323-331 (2018).

107. Raisch, D. W., Rafi, J. A., Chen, C. \& Bennett, C. L. Detection of cases of progressive multifocal leukoencephalopathy associated with new biologicals and targeted cancer therapies from the FDA's adverse event reporting system. Expert Opin. Drug Saf. 15 1003-1011 (2016)

108. Ho, P.-R. et al. Risk of natalizumab-associated progressive multifocal leukoencephalopathy in patients with multiple sclerosis: a retrospective analysis of data from four clinical studies. Lancet Neurol. 16, 925-933 (2017).

109. Boren, E. J., Cheema, G. S., Naguwa, S. M., Ansari, A. A. \& Gershwin, M. E. The emergence of progressive multifocal leukoencephalopathy $(\mathrm{PML})$ in rheumatic diseases. J. Autoimmun 30, 90-98 (2008).

110. Wijburg, M. T. et al. Performance of PML diagnostic criteria in natalizumab-associated PML: data from the Dutch-Belgian cohort. J. Neurol. Neurosurg. Psychiatry 90, 44-46 (2019).

111. Clifford, D. B et al Natalizumab-associated progressive multifocal leukoencephalopathy in patients with multiple sclerosis: lessons from 28 cases. Lancet Neurol. 9, 438-446 (2010)

112. Yousry, T. A. et al. Magnetic resonance imaging pattern in natalizumab-associated progressive multifocal leukoencephalopathy. Ann. Neurol. 72 779-787 (2012)

113. Wattjes, M. P. et al. The chameleon of neuroinflammation: magnetic resonance imaging characteristics of natalizumab-associated progressive multifocal leukoencephalopathy. Mult. Scler. 19 , 1826-1840 (2013)

114. Wattjes, M. P. $\&$ Barkhof, F. Diagnosis of natalizumabassociated progressive multifocal leukoencephalopath using MRI. Curr. Opin. Neurol. 27, 260-270 (2014).

115. Wattjes, M. P. et al. MRI characteristics of early PMLIRIS after natalizumab treatment in patients with MS. J. Neurol. Neurosurg. Psychiatry 87, 879-884 (2016).

116. Bloomgren, G. et al. Risk of natalizumab-associated progressive multifocal leukoencephalopathy. N. Engl. J. Med. 366, 1870-1880 (2012)

117. Campagnolo, D. et al. Statistical analysis of PML incidences of natalizumab-treated patients from 2009 to 2016: outcomes after introduction of the Stratify $\mathrm{JCV}^{\circledast}$ DxSelect ${ }^{\mathrm{Th}}$ antibody assay. J. Neurovirol. 22, 880-881 (2016)

118. Plavina, T. et al. Anti-JC virus antibody levels in serum or plasma further define risk of natalizumab-associated progressive multifocal leukoencephalopathy. Ann. Neurol. 76, 802-812 (2014).

119. Ryerson, L. Z. et al. Risk of natalizumab-associated PML in patients with MS is reduced with extended interval dosing. Neurology 93, e1452-e1462 (2019).

120. Phan-Ba, R. et al. The earlier, the smaller, the better for natalizumab-associated PML: in MRI vigilance veritas? Neurology 79, 1067-1069 (2012).

121. Havla, J., Hohlfeld, R. \& Kümpfel, T. Unusual natalizumab-associated progressive multifocal leukoencephalopathy starting in the brainstem. J. Neurol. 261, 232-234 (2014).

122. Blair, N. F., Brew, B. J. \& Halpern, J.-P. Natalizumabassociated PML identified in the presymptomatic phase using MRI surveillance. Neurology $\mathbf{7 8}$, 507-508 (2012).
123. Phan-Ba, R. et al. MRI preclinical detection and asymptomatic course of a progressive multifocal leucoencephalopathy (PML) under natalizumab therapy. J. Neurol. Neurosurg. Psychiatry $\mathbf{8 3}$, 224-226 (2012)

124. Vennegoor, A. et al. Indolent course of progressive multifocal leukoencephalopathy during natalizumab treatment in MS. Neurology 76, 574-576 (2011).

125. Bayliss, J., Karasoulos, T. \& McLean, C. A. Immunosuppression increases JC polyomavirus large $T$ antigen DNA load in the brains of patients without progressive multifocal leukoencephalopathy. J. Infect. Dis. 207, 133-136 (2013).

126. Wattjes, M. P. et al. MRI pattern in asymptomatic natalizumab-associated PML. J. Neurol. Neurosurg. Psychiatry 86, 793-798 (2015).

127. Dong-Si, T. et al. Outcome and survival of asymptomatic PML in natalizumab-treated MS patients. Ann. Clin. Transl. Neurol. 1, 755-764 (2014).

128. Wijburg, M. T et al. Association of progressive multifocal leukoencephalopathy lesion volume with JC virus polymerase chain reaction results in cerebrospina fluid of natalizumab-treated patients with multiple sclerosis. JAMA Neurol. 75, 827-833 (2018).

129. Wattjes, M. P. et al. Diagnosis of asymptomatic natalizumab-associated PML: are we between a rock and a hard place? J. Neurol. 261, 1139-1143 (2014).

130. McGuigan, C. et al. Stratification and monitoring of natalizumab-associated progressive multifocal leukoencephalopathy risk: recommendations from an expert group. J. Neurol. Neurosurg. Psychiatry $\mathbf{8 7}$, 117-125 (2016)

131. Du Pasquier, R. A. et al. Productive infection of cerebellar granule cell neurons by JC virus in an HIV+ individual. Neurology 61, 775-782 (2003).

132. Wuthrich, C. et al. Frequent infection of cerebellar granule cell neurons by polyomavirus JC in progressiv multifocal leukoencephalopathy. J. Neuropathol. Exp. Neurol. 68, 15-25 (2009).

133. Wijburg, M. T. et al. Heterogeneous imaging characteristics of JC virus granule cell neuronopathy $(\mathrm{GCN})$ : a case series and review of the literature. J. Neurol. 262, 65-73 (2015)

134. Wijburg, M. T., Siepman, D., van Eijk, J. J. J. Killestein, J. \& Wattjes, M. P. Concomitant granule cell neuronopathy in patients with natalizumab-associated PML. J. Neurol. 263, 649-656 (2016).

135. Richardson, E. P. \& Webster, H. D. Progressive multifocal leukoencephalopathy: its pathological features. Prog. Clin. Biol. Res. 105, 191-203 (1983).

136. Dang, X. \& Koralnik, I. J. A granule cell neuronassociated $J C$ virus variant has a unique deletion in the VP1 gene. J. Gen. Virol. 87, 2533-2537 (2006).

137. Dang, X. et al. JC virus granule cell neuronopathy is associated with VP1 C terminus mutants. J. Gen. Virol. 93, 175-183 (2012).

138. Koralnik, I. J. et al. JC virus granule cell neuronopathy: a novel clinical syndrome distinct from progressive multifocal leukoencephalopathy. Ann. Neurol. 57, 576-580 (2005)

139. Wuthrich, C. et al. Fulminant JC virus encephalopathy with productive infection of cortical pyramidal neurons. Ann. Neurol. 65, 742-748 (2009).

140. Reoma, L. B. et al. Fatal encephalopathy with wild-type JC virus and ruxolitinib therapy. Ann. Neurol. 86, 878-884 (2019)

141. Dang, X., Wuthrich, C., Gordon, J., Sawa, H. \& Koralnik, I. J. JC virus encephalopathy is associated with a novel agnoprotein-deletion JCV variant. PLoS One 7, e35793 (2012)

142. Blake, K. et al. JC virus associated meningoencephalitis in an immunocompetent girl. Arch. Dis. Child. 67 , 956-957 (1992)

143. Behzad-Behbahani, A., Klapper, P. E., Vallely, P. J., Cleator, G. M. \& Bonington, A. BKV-DNA and JCV DNA in CSF of patients with suspected meningitis or encephalitis. Infection 31, 374-378 (2003).

144. Viallard, J.-F., Ellie, E., Lazaro, E., Lafon, M.-E. \& Pellegrin, J.-L. JC virus meningitis in a patient with systemic lupus erythematosus. Lupus 14, 964-966 (2005).

145. Agnihotri, S. P. et al. A fatal case of JC virus meningitis presenting with hydrocephalus in a human immunodeficiency virus-seronegative patient. Ann. Neurol. 76, 140-147 (2014).

146. Corbridge, S. M. et al. JC virus infection of meningeal and choroid plexus cells in patients with progressive multifocal leukoencephalopathy. J. Neurovirol. 25, 520-524 (2019).
147. Wuthrich, C., Batson, S. \& Koralnik, I. J. Lack of major histocompatibility complex class I upregulation and restrictive infection by $\mathrm{JC}$ virus hamper detection of neurons by $\mathrm{T}$ lymphocytes in the central nervous system. J. Neuropathol. Exp. Neurol. 74, 791-803 (2015).

148. Hall, C. D. et al. Failure of cytarabine in progressive multifocal leukoencephalopathy associated with human immunodeficiency virus infection. N. Engl. J. Med. 338, 1345-1351 (1998).

149. Royal, W. et al. Topotecan in the treatment of acquired immunodeficiency syndrome-related progressive multifocal leukoencephalopathy. J. Neurovirol. 9 , 411-419 (2003)

150. Gasnault, J. et al. Improved survival of HIV-1-infected patients with progressive multifocal leukoencephalopathy receiving early 5-drug combination antiretroviral therapy. PLoS One 6, e20967 (2011).

151. Clifford, D. B. et al. A study of mefloquine treatment for progressive multifocal leukoencephalopathy: results and exploration of predictors of PML outcomes. J. Neurovirol. 19, 351-358 (2013)

152. De Luca, A. et al. Cidofovir in addition to antiretrovira treatment is not effective for AIDS-associated progressive multifocal leukoencephalopathy: a multicohort analysis. AIDS 22, 1759-1767 (2008)

153. Jamilloux, Y. et al. Treatment of progressive multifocal leukoencephalopathy with mirtazapine. Clin. Drug Investig. 36, 783-789 (2016)

154. Landi, D. et al. No evidence of beneficial effects of plasmapheresis in natalizumab-associated PML. Neurology 88, 1144-1152 (2017).

155. Scarpazza, C. et al. To do or not to do? plasma exchange and timing of steroid administration in progressive multifocal leukoencephalopathy. Ann Neurol. 82, 697-705 (2017).

156. Przepiorka, D et al. Successful treatment of progressive multifocal leukoencephalopathy with low-dose interleukin-2. Bone Marrow Transpl. 20 983-987 (1997).

157. Re, D. et al. Progressive multifocal leukoencephalopathy after autologous bone marrow transplantation and alpha-interferon immunotherapy. Bone Marrow Transpl. 23, 295-298 (1999).

158. Buckanovich, R. J. et al. Nonmyeloablative allogeneic stem cell transplantation for refractory Hodgkin's lymphoma complicated by interleukin-2 responsive progressive multifocal leukoencephalopathy. Ann. Hematol. 81, 410-413 (2002).

159. Kunschner, L. \& Scott, T. F. Sustained recovery of progressive multifocal leukoencephalopathy after treatment with IL-2. Neurology 65, 1510-1510 (2005).

160. Stefoski, D. et al. Treatment of natalizumab-associated PML with filgrastim. Ann. Clin. Transl. Neurol. 6, 923-931 (2019)

161. Gasnault J., et al. Efficacy of recombinant human interleukin 7 in a patient with severe lymphopeniarelated progressive multifocal leukoencephalopathy. Open Forum Infect. Dis. https://doi.org/10.1093/ofid/ ofu074 (2014)

162. Miskin, D. P. et al. Interleukin-7 treatment of PML in a patient with idiopathic lymphocytopenia. Neurol. Neuroimmunol. Neuroinflamm. 3, e213 (2016).

163. Soleimani-Meigooni, D. N. et al. JC virus granule cell neuronopathy in the setting of chronic lymphopenia treated with recombinant interleukin-7. J. Neurovirol. 23, 141-146 (2017).

164. Harel, A. et al. Successful treatment of progressive multifocal leukoencephalopathy with recombinant interleukin-7 and maraviroc in a patient with idiopathic CD4 lymphocytopenia. J. Neurovirol. 24 652-655 (2018)

165. Patel, A., Patel, J. \& Ikwuagwu, J. A case of progressive multifocal leukoencephalopathy and idiopathic CD4+ lymphocytopenia. J. Antimicrob. Chemother. 65, 2697-2698 (2010).

166. Sospedra, M. et al. Treating progressive multifocal leukoencephalopathy with interleukin 7 and vaccination with JC virus capsid protein VP1. Clin. Infect. Dis. 59, 1588-1592 (2014).

167. Mackall, C. L., Fry, T. J. \& Gress, R. E. Harnessing the biology of IL-7 for therapeutic application. Nat. Rev. Immunol. 11, 330-342 (2011)

168. Cortese, I. et al. Pembrolizumab treatment for progressive multifocal leukoencephalopathy. N. Engl. J. Med. 380, 1597-1605 (2019).

169. Pawlitzki, M. et al. Ineffective treatment of PML with pembrolizumab: exhausted memory T-cell subsets as a clue? Neurol. Neuroimmunol. Neuroinflamm. 6, e627 (2019). 
170. Nagai, H. \& Muto, M. Optimal management of immune-related adverse events resulting from treatment with immune checkpoint inhibitors: a review and update. Int. J. Clin. Oncol. 23, 410-420 (2018)

171. Balduzzi, A. et al. Polyomavirus JC-targeted T-cell therapy for progressive multiple leukoencephalopathy in a hematopoietic cell transplantation recipient. Bone Marrow Transpl. 46, 987-992 (2011).

172. Muftuoglu, M. et al. Allogeneic BK virus-specific T cells for progressive multifocal öeukoencephalopathy. N. Engl. J. Med. 379, 1443-1451 (2018).

173. US National Library of Medicine. ClinicalTrials.gov https://clinicaltrials.gov/ct2/show/NCT02694783 (2020)

174. McLaughlin, L. P., Bollard, C. M. \& Keller, M. Adoptive $T$ cell immunotherapy for patients with primary immunodeficiency disorders. Curr. Allergy Asthma Rep. 17, 3 (2017).

175. Ottaviano, G. et al. Adoptive T cell therapy strategies for viral infections in patients receiving haematopoietic stem cell transplantation. Cells. 8, 47 (2019).

176. Antoniol, C. et al. Impairment of JCV-specific T-cell response by corticotherapy: effect on PML-IRIS management? Neurology 79, 2258-2264 (2012).

177. Berger, J. R. Steroids for PML-IRIS: a double-edged sword? Neurology 72, 1454-1455 (2009).

178. Johnson, T. $\&$ Nath, A. Neurological complications of immune reconstitution in HIV-infected populations. Ann. NY Acad. Sci. 1184, 106-120 (2010).

179. Koralnik, I. J. \& Clifford, D. B. Comment: avoiding detrimental effects of corticosteroids on JC virus T-cell responses-primum non nocere. Neurology 79 , 2263-2263 (2012)

180. Giacomini, P. S. et al. Maraviroc and JC virusassociated immune reconstitution inflammatory syndrome. N. Engl. J. Med. 370, 486-488 (2014).

181. Bsteh, G. et al. Severe early natalizumab-associated PML in MS: effective control of PML-IRIS with maraviroc. Neurol. Neuroimmunol. Neuroinflamm. 4 , e323 (2017)

182. Hodecker, S. C. et al. Maraviroc as possible treatment for PML-IRIS in natalizumab-treated patients with MS Neurol. Neuroimmunol. Neuroinflamm. 4, e325 (2017).

183. Scarpazza, C. et al. Is maraviroc useful in multiple sclerosis patients with natalizumab-related progressive multifocal leukoencephalopathy? J. Neurol. Sci. $\mathbf{3 7 8}$, 233-237 (2017)

184. Rodríguez, M. et al. Maraviroc failed to control progressive multifocal leukoencephalopathyassociated IRIS in a patient with advanced HIV infection. Case Rep. Med. 2014, 381480-381483 (2014).

185. Lima, M. A., Bernal-Cano, F., Clifford, D. B. Gandhi, R. T. \& Koralnik, I. J. Clinical outcome of longterm survivors of progressive multifocal leukoencephalopathy. J. Neurol. Neurosurg. Psychiatry 81, 1288-1291 (2010).

186. Vermersch, P. et al. Clinical outcomes of natalizumab-associated progressive multifocal leukoencephalopathy. Neurology 76, 1697-1704 (2011).

187. Anand, P. Hotan, G. C., Vogel, A., Venna, N. \& Mateen, F. J. Progressive multifocal leukoencephalopathy: A 25-year retrospective cohort study. Neurol. Neuroimmunol. Neuroinflamm. 6, e618 (2019).

188. Delbue, S. et al. JC virus load in cerebrospinal fluid and transcriptional control region rearrangements may predict the clinical course of progressive multifocal leukoencephalopathy. J. Cell Physiol. 227, 3511-3517 (2012).

189. Schneider, R. et al. Metabolic profiles by $1 \mathrm{H}$-magnetic resonance spectroscopy in natalizumab-associated post-PML lesions of multiple sclerosis patients who survived progressive multifocal leukoencephalopathy (PML). PLoS One 12, e0176415 (2017).

190. Gray, F., Chrétien, F., Vallat-Decouvelaere, A. V. $\&$ Scaravilli, F. The changing pattern of HIV neuropathology in the HAART era. J. Neuropathol. Exp. Neurol. 62, 429-440 (2003).

191. Schmidbauer, M., Budka, H. \& Shah, K. V. Progressive multifocal leukoencephalopathy (PML) in AIDS and in the pre-AIDS era. A neuropathological comparison using immunocytochemistry and in situ DNA hybridization for virus detection. Acta Neuropathol. 80, 375-380 (1990)

192. Maillart, E. et al. Natalizumab-PML survivors with subsequent MS treatment: clinico-radiologic outcome Neurol. Neuroimmunol. Neuroinflamm. 4, e346 (2017).
193. Rosenkranz, T., Novas, M. \& Terborg, C. PML in a patient with lymphocytopenia treated with dimethyl fumarate. N. Engl. J. Med. 372, 1476-1478 (2015)

194. US Food and Drug Administration. FDA drug safety communication: FDA warns about cases of rare brain infection with MS drug Gilenya (fingolimod) in two patients with no prior exposure to immunosuppressant drugs. https://www.fda.gov/drugs/drug-safety-andavailability/fda-drug-safety-communication-fdawarns-about-cases-rare-brain-infection-ms-druggilenya-fingolimod (2015).

195. Molloy, E. S. \& Calabrese, L. H. Progressive multifocal leukoencephalopathy: a national estimate of frequency in systemic lupus erythematosus and other rheumatic diseases. Arthritis Rheum. 60, 3761-3765 (2009).

Acknowledgements

This work was supported by the Intramural Research Program of the NIH, NINDS.

\section{Author contributions}

I.C. researched data for the article and wrote the manuscript. All authors made substantial contributions to discussion of the content and reviewed and/or edited the manuscript before submission.

\section{Competing interest}

The authors declare no competing interests.

\section{Peer review information}

Nature Reviews Neurology thanks I. Koralnik, K. Nakamichi and $\mathrm{M}$. Wattjes for their contribution to the peer review of this work.

\section{Publisher's note}

Springer Nature remains neutral with regard to jurisdictional claims in published maps and institutional affiliations.

\section{RELATED LINK}

Biogen Medical Information: https://medinfo.biogen.com

This is a U.S. government work and not under copyright protection in the U.S.; foreign copyright protection may apply 2020 